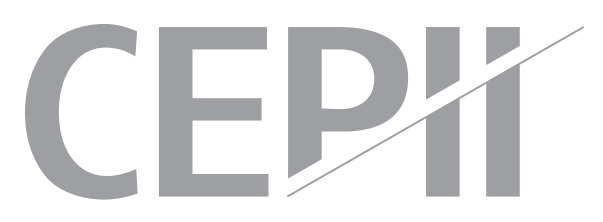

\title{
Does the volatility of commodity prices reflect macroeconomic uncertainty?
}

\author{
Marc Joëts, Valérie Mignon \& Tovonony Razafindrabe
}

\section{Highlights}

-We analyze the impact of macroeconomic uncertainty on a large sample of 19 commodity markets.

- The safe-haven role of precious metals is confirmed, while agricultural and industrial markets are markets are highly sensitive to the variability and the level of macroeconomic uncertainty, respectively.

- The recent 2007-09 recession has generated an unprecedented episode of high uncertainty in numerous commodity markets that is not necessarily accompanied by a subsequent volatility in the corresponding prices. 


\section{Abstract}

This paper analyzes the impact of macroeconomic uncertainty on a large sample of 19 commodity markets. We rely on a robust measure of macroeconomic uncertainty based on a wide range of monthly macroeconomic and financial indicators, and we estimate a structural threshold VAR (TVAR) model to assess whether the effect of macroeconomic uncertainty on commodity price returns depends on the degree of uncertainty. Our findings show that whereas the safe-haven role of precious metals is confirmed, agricultural and industrial markets are highly sensitive to the variability and the level of macroeconomic uncertainty, respectively. In addition, we show that the recent 2007-09 recession has generated an unprecedented episode of high uncertainty in numerous commodity markets that is not necessarily accompanied by a subsequent volatility in the corresponding prices, highlighting the relevance of our uncertainty measure in linking uncertainty to predictability rather than to volatility.

\section{Keywords}

Macroeconomic uncertainty, commodity prices, threshold vector autoregressive model.

\section{JEL}

Q02, E32, C32.

\section{Working Paper}

\section{CEPI}

CEPII (Centre d'Etudes Prospectives et d'Informations Internationales) is a French institute dedicated to producing independent, policyoriented economic research helpful to understand the international economic environment and challenges in the areas of trade policy, competitiveness, macroeconomics, international finance and growth
CEPII Working Paper

Contributing to research in international economics

C C CEPII, PARIS, 2015

All rights reserved. Opinions expressed in this publication are those of the author(s) alone.

$\begin{array}{ll}\text { Editorial Director: } & \text { CEPII } \\ \text { Sébastien Jean } & \begin{array}{l}113, \text { rue de Grenelle } \\ 75007 \text { Paris }\end{array} \\ \text { Production: } & +33153685500 \\ \text { Laure Boivin } & \text { www.cepii.fr } \\ \text { No ISSN: } 1293-2574 & \text { Press contact: presse@ }\end{array}$




\title{
Does the volatility of commodity prices reflect macroeconomic uncertainty ${ }^{1}$
}

\author{
Marc Joëts*, Valérie Mignon ${ }^{\dagger}$ and Tovonony Razafindrabe $\ddagger$
}

\section{Introduction}

Uncertainty has been widely documented in the economics literature, particularly its transmission mechanism to activity, which has been extensively discussed both theoretically and empirically. For instance, theories of investment under uncertainty explain why under irreversibility condition or fixed costs, uncertainty over future returns reduces current investment, hiring, and consumption through an "option value to wait". ${ }^{2}$ At a micro level, increased uncertainty may diminish the willingness of firms to commit resources to irreversible investment and the readiness of consumers to spend or allocate their earning and wages. Such uncertainty at a micro level may also be transmitted to the macro level, as shown by Bernanke (1983), arguing that uncertainty about the return to investment at a micro level may create cyclical fluctuations in aggregate investment at a macro level. ${ }^{3}$

In the wake of this literature, our aim in this paper is to investigate the impact of uncertainty on commodity markets. Regarding the previous literature, two classes of papers have highlighted the significance of uncertainty in oil prices in explaining economic fluctuations as well as its role in exacerbating asymmetry in the oil price-economic activity nexus. ${ }^{4}$ The

\footnotetext{
${ }^{1}$ We are grateful to Nathan Balke for providing us with his code for the TVAR estimations. We would like to thank Nick Bloom, Soojin Jo, and Lutz Kilian for their constructive comments and suggestions that helped us improve an earlier version of the paper. The usual disclaimers apply.

*Ipag Lab, IPAG Business School and EconomiX-CNRS, University of Paris Ouest, France. E-mail: marc. joets@ipag.fr

†EconomiX-CNRS, University of Paris Ouest and CEPII, France. Corresponding author: Valérie Mignon, EconomiX-CNRS, University of Paris Ouest, 200 avenue de la République, 92001 Nanterre Cedex, France. Phone: 331409758 60. E-mail: valerie.mignon@u-paris10.fr

${ }^{\ddagger}$ EconomiX-CNRS, University of Paris Ouest, France. E-mail: trazafindrab@u-paris10.fr

2See Henry (1974), Bernanke (1983), Brennan and Schwartz (1985), Majd and Pindyck (1987), Brennan (1990), Gibson and Schwartz (1990), Bloom et al. (2007), Bloom (2009), Edelstein and Kilian (2009), and Bredin et al. (2011) among others.

${ }^{3}$ This could be due to two reasons: (i) the macroeconomy is insufficiently diversified and cannot be protected from micro-level fluctuations (see Gabaix, 2011); and (ii) under imperfect information, agents may confound transitory and permanent shocks, thereby converting a transitory shock into a persistent shock.

${ }^{4}$ Considering the uncertainty channel, the asymmetric responses of real output to oil price shocks may come
} 
first strand of studies is based on the volatility of the real price of oil at medium- and long-term horizons, i.e. at horizons that are relevant to purchase and investment decisions. In this vein, the theoretical models of Bernanke (1983) and Pindyck (1991) suggest that oil price uncertainty was the main cause of the 1980 and 1982 recessions. ${ }^{5}$ The second strand of the literature is empirical and based on short-term uncertainty. Elder and Serletis $(2009,2010)$ were among the first to provide a fully specified model for the impact of oil price uncertainty on real GDP. Using a structural vector autoregressive (SVAR) model for post-1980 data, they find empirical evidence that uncertainty about oil price evolution tends to depress output, investment, and consumption in the U.S. and the G-7 countries in an asymmetric way. ${ }^{6}$ They also show that the net effect of an unexpected drop in the real price of oil is to cause recessions, a result which is not in line with the economic theory. ${ }^{7}$ Relying on a quarterly vector autoregressive (VAR) model with stochastic volatility in the mean, Jo (2014) finds far much smaller uncertainty effect on world industrial production than Elder and Serletis (2010). The author points out that Elder and Serletis (2010)'s GARCH-in mean VAR is misspecified because the same model is driving both the conditional mean and the conditional variance. While providing interesting results, these models suffer from an important drawback regarding the supposed role of oil price shocks in explaining recessions. Indeed, as underlined by Kilian and Lewis (2011) and Kilian (2014), the empirical literature does not consider that recessionary episodes are driven by sequences of oil price shocks of different magnitude and sign. In addition, as argued by Kilian (2014), energy is not necessarily a key component of the cash flow of investment projects, making the effect of oil price uncertainty on output not plausible. Theoretically, the existent measures of price uncertainty also raise some important issues since they are constructed at short-run horizons (month-ahead) rather than at horizons relevant to purchase and investment decisions (years) (see Kilian and Vigfusson, 2011a).

As can be seen, the previous literature has faced some limitations in explaining uncertainty in oil prices and its impact on economic activity. The reverse effect, namely, the influence of macroeconomic uncertainty on oil price fluctuations, has not been widely addressed through this question is of particular interest given the modern view that the price of oil

from the fact that uncertainty tends to amplify the effect of unexpected oil price increases and offset the impact of unexpected oil price decreases (see Kilian, 2014).

${ }^{5}$ It should be noticed that Bernanke (1983) and Pindyck (1991) consider the oil price as exogenous with respect to the U.S. economy, which is not consistent with the recent literature about the endogenous component of oil prices (see Kilian, 2008a).

${ }^{6}$ As noticed by Kilian (2014), Elder and Serletis do not directly test for symmetry in the effect of oil prices, but rather test the null of no feedback effect from the conditional variance of oil prices to the conditional mean.

${ }^{7}$ Other empirical papers exist in the literature, such as Favero et al. (1994), Lee et al. (1995), and Ferderer (1996), but they either treat oil as exogenous or use data from the pre-1973 period. 
is characterized by an important endogenous component. Some exceptions can, however, be mentioned. Regarding first the theoretical papers, (i) Pindyck (1980) discusses the theoretical implications of uncertainty associated with oil demand and reserves on the oil price behavior; (ii) Litzenberger and Rabinowitz (1995) analyze backwardation behavior in oil futures contracts; and (iii) Alquist and Kilian (2010) allow for endogenous convenience yield and endogenous inventories, and stress that it is uncertainty about the shortfall of supply relative to demand that matters. Turning to the empirical papers, one may refer to (i) Kilian (2009) and Kilian and Murphy (2014) who design as a precautionary demand shock a shock that reflects shifts in uncertainty and treat macroeconomic uncertainty as unobserved; and (ii) Van Robays (2013) who investigates whether observed macroeconomic uncertainty changes the responsiveness of the oil price to shocks in oil demand and supply.

Considering the impact of macroeconomic uncertainty on commodity markets, our paper contributes to this literature and extends it in several ways. As previously mentioned, though most of the literature has focused on the incidence of oil price uncertainty on economic activity, we address the reverse effect by examining the influence of macroeconomic uncertainty not only on oil prices but also on a large panel of commodity markets. More specifically, we consider four groups of 19 raw materials (energy, precious metals, agriculture, and industry) to investigate whether the impact of macroeconomic uncertainty on commodity prices differs depending on the type of market. With uncertainty evolving through time, we account for this feature by assessing its impact at various horizonsnamely short-, medium-, and long-run horizons - to test whether its effect varies according to its maturity. From a theoretical viewpoint, fluctuations in uncertainty may indeed have different impacts through time (see Bloom, 2014). Usually, two negative channels for uncertainty to influence growth are at play in the short run, and two positive channels exist in the medium and long run. The real option and the risk aversion/risk premium channels are often discussed in the empirical literature as the main consequences that uncertainty damages growth in the short run. ${ }^{8}$ Turning to the long-run positive channels of uncertainty influence, they generally rely on the growth option and Oi-Hartman-Abel effects, although the conclusive evidence is more parsimonious. ${ }^{9}$ Regarding the case of commodity markets, the interest in distinguishing between possibly different impacts of uncertainty at diverse maturities makes also more theoretical sense with respect to Bernanke-Pindyck's uncer-

\footnotetext{
${ }^{8}$ The real option hypothesis refers to an option value to wait and suggests that uncertainty encourages firms to become cautious about adjustment costs. The risk aversion/risk premium effect refers to the cost of finance, which may increase in times of greater uncertainty.

${ }^{9}$ See Bloom (2014) for a review of the related literature. The growth option argument is based on the idea that uncertainty can encourage investment and R\&D if it increases the size of the potential prize. The Oi-Hartman-Abel effect refers to the fact that firms can expand to exploit good outcomes and contract to insure against bad outcomes, diminishing the potential impact of uncertainty.
} 
tainty definition.

Turning to methodological issues, our contribution is threefold. First, we retain a nonlinear specification for modeling commodity price returns to account for potentially different effects of macroeconomic uncertainty on commodity markets depending on the environment. Specifically, we rely on a structural threshold vector autoregressive (TVAR) specification that allows us to identify different uncertainty states, and we investigate whether the impact of uncertainty varies according to its level and variability. Second, because macroeconomic uncertainty is unobservable, assessing its effect on commodity markets obviously requires us to find an adequate proxy. To this end, we rely on Jurado et al. (2014) and consider a robust approach to measuring macroeconomic uncertainty. The retained proxy uses a wide range of monthly macroeconomic and financial indicators and is based on the underlying idea of a link between uncertainty and predictability. In this sense, we go further than the previous literature ${ }^{10}$ _ particularly compared with Van Robays (2013)'s paper, which is the closest to ours - which generally relies on dispersion measures such as conditional volatility (e.g. conditional variance of world industrial production growth or of U.S. GDP growth estimated from a $\mathrm{GARCH}(1,1)$ process) or the popular $\mathrm{VXO}$ index proposed by Bloom (2009). An important drawback in using GARCH-type models to proxy uncertainty is that they are inherently backward-looking, whereas investors' expectations tend to be forward-looking. More generally, and thanks to a detailed robustness analysis, we show that the choice of the uncertainty measure is crucial to avoid erroneously attributing to uncertainty fluctuations that are actually predictable. Third, for the sake of completeness, we also investigate how macroeconomic uncertainty can generate uncertainty in commodity prices. To this end, we construct a robust proxy of commodity market uncertainty based on macroeconomic uncertainty, ${ }^{11}$ and provide a historical decomposition that allows us to determine the contribution of macroeconomic uncertainty to commodity price uncertainty.

The rest of the paper is organized as follows. Section 2 presents the uncertainty measure and discusses the corresponding theoretical framework. Section 3 addresses methodological issues by presenting the TVAR specification as well as our data. Section 4 displays the results regarding the impact of macroeconomic uncertainty on commodity markets. Section 5 is devoted to the link between macroeconomic uncertainty and the uncertainty of each commodity market. Section 6 provides some robustness checks regarding the choice of both the macroeconomic uncertainty measure and our measure of price uncertainty. Finally, Section 6 concludes the paper.

\footnotetext{
${ }^{10}$ See references in Section 2.

${ }^{11}$ This approach is therefore theoretically robust to the endogenous component of commodity prices, in line with the recent literature (see references in Section 2).
} 


\section{Uncertainty measure}

\subsection{Measuring macroeconomic uncertainty}

Measuring uncertainty and examining its impact on market dynamics is a challenging question for economists because no objective measure exists. Although in a general sense uncertainty is defined as the conditional volatility of an unforecastable disturbance, ${ }^{12}$ the empirical literature to date has usually relied on proxies. The most common measures used are the implied or realized volatility of stock market returns, the cross-sectional dispersion of firm profits, stock returns, or productivity, and the cross-sectional dispersion of survey-based forecasts. ${ }^{13}$ However, their adequacy to correctly proxy uncertainty is questionable, and such measures are even misspecified with regard to the theoretical notion of uncertainty, as highlighted by Jurado et al. (2014). Indeed, stock market volatility, cross-sectional dispersion in stock returns and firm profits can vary over time due to several factors - such as risk aversion, the leverage effect, and heterogeneity between firms-even if there is no significant change in uncertainty. In other words, fluctuations that are actually predictable can be erroneously attributed to uncertainty, putting forward the importance of distinguishing between uncertainty in a series and its conditional volatility. Specifically, properly measuring uncertainty requires to remove the forecastable component of the considered series before computing the conditional volatility. In this sense, uncertainty in a series is not equivalent to the conditional volatility of the raw series. ${ }^{14}$ Another important characteristic of Jurado et al. (2014)'s approach is that macroeconomic uncertainty is defined as the common variation in uncertainty across many series rather than uncertainty related to any single series. This is in line with the uncertainty-based business cycle theories which implicitly assume a common variation in uncertainty across a large number of series. ${ }^{15}$

Accordingly, to provide a consistent measure of macroeconomic uncertainty, we follow the definition of Jurado et al. (2014) by linking uncertainty to predictability. Specifically, the $h$-period-ahead uncertainty in the variable $y_{j t} \in Y_{t}=\left(y_{1 t}, \ldots, y_{N_{y} t}\right)^{\prime}$ is defined as the

\footnotetext{
${ }^{12}$ See Bloom (2009), Bloom et al. (2010), Gilchrist et al. (2010), Arellano et al. (2011), Bachmann and Bayer (2011), Baker et al. (2011), Basu and Bundick (2011), Knotek and Khan (2011), Fernandez-Villaverde et al. (2011), Schaal (2012), Bloom et al. (2012), Leduc and Liu (2012), Nakamura et al. (2012), Bachmann et al. (2013), and Orlik and Veldkamp (2013) among others.

${ }^{13}$ See Jurado et al. (2014). The papers cited in Section 1 related to the study of the relationship between uncertainty and oil prices have used such indicators.

${ }^{14}$ As discussed by Jurado et al. (2014), almost all proxies used in the literature do not make this distinction, while this is a crucial issue as we will see in Section 6.

${ }^{15}$ This is also typically different to what the literature has defined so far by considering either macroeconomic uncertainty as the stochastic volatility of aggregate shocks or imposing a countercyclical component in the volatility of individual disturbances.
} 
conditional volatility $U_{j t}^{y}(h)$ of the purely unforecastable component of the future value of the series:

$$
U_{j t}^{y}(h) \equiv \sqrt{E\left[\left(y_{j t+h}-E\left[y_{j t+h} \mid J_{t}\right]\right)^{2} \mid J_{t}\right]},
$$

where $j=1, \ldots, N_{y}, E\left(. \mid J_{t}\right)$ is the conditional expectation of the considered variable and $J_{t}$ denotes the information set available at time $t$. Uncertainty related to the variable $y_{j t+h}$ is therefore defined as the expectation of the squared error forecast. Aggregating over $j$ individual uncertainty measures $U_{j t}^{y}(h)$ equally weighted by $w_{j}$ leads to the following expression of aggregate or macroeconomic uncertainty:

$$
U_{t}^{y}(h) \equiv \operatorname{plim}_{N_{y} \rightarrow \infty} \sum_{j=1}^{N_{y}} w_{j} U_{j t}^{y}(h) \equiv E_{w}\left[U_{j t}^{y}(h)\right] .
$$

As discussed by Jurado et al. (2014), the estimation of Equations (1) and (2) requires three fundamental steps. The first step is to replace the conditional expectation $E\left[y_{j t+h} \mid J_{t}\right]$ in Equation (1) by a forecast in order to compute forecast errors. It is a crucial step since the forecastable component should be then removed from the conditional volatility computation. ${ }^{16}$ To do so, an as rich as possible predictive model based on factors from a large set of $N$ predictors $\left\{X_{i t}\right\}, i=1, \ldots, N$, is considered, taking the following approximated form:

$$
X_{i t}=\Lambda_{i}^{F^{\prime}} F_{t}+e_{i t}^{X}
$$

where $F_{t}$ is a $r_{f} \times 1$ vector of latent common factors, $\Lambda_{i}^{F}$ is the vector of latent factor loadings, and $e_{i t}^{X}$ is a vector of idiosyncratic errors which allows for some cross-sectional correlations. To account for time-varying omitted-information bias, Jurado et al. (2014) further include estimated factors, as well as non-linear functions of these factors in the forecasting model through a diffusion forecast index. ${ }^{17}$ The second step consists of (i) defining the $h$-step-ahead forecast error by $V_{j t+h}^{y}=y_{j t+h}-E\left[y_{j t+h} \mid J_{t}\right]$, and (ii) estimating the related conditional volatility, namely $E\left[\left(V_{t+h}^{y}\right)^{2} \mid J_{t}\right]$. To account for time-varying volatility in the errors of the predictor variables, $E\left[\left(V_{t+h}^{y}\right)^{2} \mid J_{t}\right]$ is recursively multistep-ahead com-

\footnotetext{
${ }^{16}$ Recall that removing the forecastable component of $y_{j t}$ is crucial to avoid erroneously categorizing predictable variations as uncertain.

${ }^{17}$ This approach is widely used in data-rich environments.
} 
puted for $h>1 .{ }^{18}$ In the third, final step, macroeconomic uncertainty $U_{t}^{y}(h)$ is constructed from the individual uncertainty measures $U_{j t}^{y}(h)$ through an equally-weighted average.

Using large datasets on economic activity, Jurado et al. (2014) provide two types of uncertainty measures that are as free as possible from both the restrictions of theoretical models and/or dependencies on a handful of economic indicators. The first one is the "common macroeconomic uncertainty" based on the information contained in hundreds of primarily macroeconomic and financial monthly indicators, ${ }^{19}$ and the second one is the "common microeconomic uncertainty" based on 155 quarterly firm-level observations on profit growth normalized by sales. ${ }^{20}$ Empirically, these measures have the advantage of providing far fewer important uncertainty episodes than do popular proxies. As an example, though Bloom (2009) identifies 17 uncertainty periods based on stock market volatility, Jurado et al. (2014) find evidence of only three episodes of uncertainty over the 19592011 period: the month surrounding the 1973-74 and 1981-82 recessions and the recent 2007-09 great recession. As stressed above, this illustrates that popular uncertainty proxies based on volatility measures usually erroneously attribute to uncertainty fluctuations that are actually forecastable. In addition, with the proposed measures defined for different values of $h$, they allow us to investigate uncertainty transmission in commodity markets for distinct maturities.

\subsection{Endogenous and exogenous components of uncertainty}

One important issue when investigating the impact of macroeconomic uncertainty on commodity prices is to understand the intrinsic nature of uncertainty with respect to prices. In

\footnotetext{
${ }^{18}$ From a statistical viewpoint, it is worth noting that time-varying uncertainty is decomposed into four sources: an autoregressive component, a common factor component, a stochastic volatility component, and a covariance term. See Jurado et al. (2014) for more details regarding the statistical decomposition of uncertainty.

${ }^{19}$ More specifically, 132 macroeconomic time series are considered, including real output and income, employment and hours, real retail, manufacturing and trade sales, consumer spending, housing starts, inventories and inventory sales ratios, orders and unfilled orders, compensation and labor costs, capacity utilization measures, price indexes, bond and stock market indexes, and foreign exchange measures. Turning to the financial indicators, 147 time series are retained, including dividend-price and earning-price ratios, growth rates of aggregate dividends and prices, default and term spreads, yields on corporate bonds of different ratings grades, yields on Treasuries and yield spreads, and a broad cross-section of industry equity returns. Both sets of data are used to estimate the forecasting factors, but macroeconomic uncertainty is proxied using the 132 macroeconomic time series only.

${ }^{20}$ Dealing with monthly data and focusing on macroeconomic uncertainty, we consider in this paper the "common macroeconomic uncertainty" measure.
} 
other words, it is important to disentangle the endogenous and exogenous components of macroeconomic uncertainty (i.e. whether macroeconomic uncertainty is demand-driven or supply-driven with respect to commodity prices). Since 1974, the price of oil-as the price of other commodities - has become endogenous with respect to global macroeconomic conditions (see Alquist et al., 2013). ${ }^{21}$ Since then, the empirical literature has provided overwhelming evidence that commodity prices have been driven by global demand shocks. ${ }^{22}$ As pointed out by Barsky and Kilian (2002), the 1973-74 episode of dramatic surge in the price of oil and industrial commodities is the most striking example where the price increase was explained for $25 \%$ by exogenous events and for $75 \%$ by shifts in the demand side. With the predominant role of flow demand on prices, another important channel of transmission is the role of expectations in the physical market. ${ }^{23}$ The underlying idea is that anyone who expects the price to increase in the future will be prompted to store oil now for future use leading to a shock from the demand of oil inventories. Kilian and Murphy (2014) demonstrate that shifts in expectations through oil inventories have played an important role during the oil price surge in 1979 and 1990, and the price collapse in 1986. ${ }^{24}$

The aggregate specification of our proxy has the particularity to be "global", accounting for a lot of information regarding uncertainty in the supply and demand channels. ${ }^{25}$ While it is quite difficult in this framework to identify the proportion of unanticipated demand or supply, some reasonable assumptions about the effect of demand and supply shocks on prices may give us some insight about the mechanisms behind the relationship between macroeconomic uncertainty and commodity prices. In our analysis, we follow the dominant view about the endogenous nature of commodity prices with respect to macroeconomic conditions, considering the aggregate demand channel as a primary source of price fluctuations (see Mabro, 1998; Barsky and Kilian, 2002, 2004; Kilian, 2008a; and Hamilton, 2009). In line with the previous literature, ${ }^{26}$ we therefore assume that exogenous events coming from the supply channel-such as cartel decisions, oil embargoes or the effects of political

\footnotetext{
${ }^{21}$ Before this date there was no global market for crude oil and the price of oil in the U.S. was regulated by the government.

${ }^{22}$ One exception for the case of oil is the 1990s, where the flow supply shocks have played an important role (see Kilian and Murphy, 2014).

${ }^{23}$ See among others, Kilian (2009), Alquist and Kilian (2010), Dvir and Rogoff (2010), Kilian and Lee (2014), and Knittel and Pindyck (2013). For a review, see Kilian (2014).

${ }^{24}$ This shock is also often called "speculative demand shock" since it involves a forward-looking strategy (see Kilian and Murphy, 2014).

${ }^{25}$ We leave aside the question of financial speculation in commodity futures markets since the empirical literature has shown that the propagation of the corresponding shock is the consequence of earlier aggregate flow demand shocks.

${ }^{26}$ Green and Porter (1984) and Rotemberg and Saloner (1986) have theoretically demonstrated that oil cartels' decisions are determined to a large extent by the macroeconomic environment. Empirically, one example is the Arab oil embargo of 1973-74 which affected the oil supply channel, and was endogenous to
} 
uncertainty from the Middle East-are secondary, being mainly an indirect consequence of the macroeconomic environment. By construction, our approach accounts for both channels, the demand channel being a direct effect of macroeconomic aggregate and the supply channel an indirect effect of macroeconomic conditions on exogenous events (see Barsky and Kilian, 2002; Alquist and Kilian, 2010; Kilian and Vega, 2011; and Kilian and Murphy, 2014). In other words, our macroeconomic uncertainty proxy primarily reflects uncertainty about the demand side. $^{27}$

\subsection{Backward-looking vs. forward-looking uncertainty}

As previously discussed, it is quite difficult to approximate uncertainty because it is not observable. One important issue regarding usual proxies based on conditional volatility is that they are often backward-looking, whereas investors' expectations tend to be forwardlooking. ${ }^{28}$ As an illustrative purpose, Figure 1 provides a comparison between three uncertainty proxies. Specifically, Panel A corresponds to the conditional volatility estimated from a one-month $\operatorname{GARCH}(1,1)$ process for the U.S. GDP growth, ${ }^{29}$ Panel B is the VXO stock market volatility index of Bloom (2009), and Panel $C$ is the common macroeconomic uncertainty proxy of Jurado et al. (2014); the gray bands corresponding to the NBER recession dates. Looking at the recent financial crisis, all proxies identify this episode as an important source of macroeconomic uncertainty since a peak occurred for each series around 2008. However, some systematic differences regarding the identified macroeconomic uncertainty periods can be highlighted. The measure based on the GARCH specification starts to peak in January 2009, while the VXO index begins to peak in May 2008. The implied volatility proxy is therefore more forward-looking than the one based on the conditional variance. ${ }^{30}$ Meanwhile, the proxy developed by Jurado et al. (2014) peaks in June 2007, pointing out that it is the most forward-looking measure. Moreover, comparing periods of uncertainty for each proxy with NBER recession dates (December 2007-June 2009), we find that both GARCH and VXO proxies are too backward-looking, while the macroeconomic uncertainty proxy we use peaks just few months before the starting date of the recession. In other words,

\footnotetext{
the U.S. economy (see Barsky and Kilian, 2002; Kilian, 2008a).

${ }^{27}$ Recall that assuming small effects for supply disruptions does not mean that exogenous political events do not matter. Indeed, they also affect prices by shifting expectations about future shortfalls of supply relative to demand (see Kilian, 2009; Alquist and Kilian, 2010; Dvir and Rogoff, 2010; Kilian and Lee, 2014; and Knittel and Pindyck, 2013).

${ }^{28}$ This point has been discussed in Kilian and Vigfusson (2011a).

${ }^{29}$ We focus on this series rather than on the world industrial production growth because it is designed to reflect the overall uncertainty of the macroeconomic environment (see Van Robays, 2013).

${ }^{30}$ This result is consistent with the literature (see e.g. Poon and Granger, 2003).
} 
our retained measure of macroeconomic uncertainty that accounts for forward-looking behavior of agents (whatever the maturity considered) is the most appropriate one, and other approaches usually erroneously attribute to uncertainty fluctuations that are actually predictable. Jurado et al. (2014) have further documented that shocks to macroeconomic uncertainty lead to an increase in the VXO index, the reverse effect being not verified. ${ }^{31}$

\subsection{The maturity effect of uncertainty}

The concept of uncertainty is basically related to the perception of agents about potential future evolutions. Together with the notion of time variability, it implies that different horizons lead to distinct perceptions of uncertainty, and thus disparate economic behaviors. As shown by Jurado et al. (2014), uncertainty is generally higher for medium- and long-run maturities (respectively 3 and 12 months) than for short-run horizons (1 month). In addition, the relative importance of macroeconomic uncertainty in the total uncertainty (i.e. uncertainty accounting for all series) grows as the forecast horizon increases. Accounting for the maturity is thus of great importance to fully apprehend the impact of uncertainty on macroeconomic dynamics. As shown by Jurado et al. (2014), uncertainty shocks with shorter uncertainty horizons tend to be associated with a larger fraction of the forecast error variance in aggregates than those with longer uncertainty horizons. ${ }^{32}$

In the context of commodity prices and especially oil prices, the discussion is of primary importance. The ongoing debate in the literature about the effect of maturity has been mainly oriented toward the consequences of oil price uncertainty on economic activity. Kilian and Vigfusson (2011a) provide an interesting comparison between the long-run theoretical uncertainty measure of Bernanke (1983) and Pindyck (1991), and the empirical shortrun uncertainty proxy of Elder and Serletis (2010). According to the authors, the former definition is related to uncertainty at horizons relevant to investment decisions, while the latter is more appropriate to capture the reallocation effect of Hamilton (1988) since it measures the current real oil price volatility. Clearly, the effect of oil price uncertainty on activity depends on the impact of the oil price on investment, but also on how companies face to uncertainty regarding their investment decision plans. Indeed, depending on the sectors, the delay from the investment decision to the beginning of the production can differ,

\footnotetext{
${ }^{31}$ See Figure 6 of Jurado et al. (2014)'s paper. Section 6.1 of our paper compares both proxies in the context of commodity prices and confirms that the predictability-based approach of Jurado et al. (2014) is more appropriated than the VXO index of Bloom (2009) to approximate macroeconomic uncertainty.

${ }^{32}$ More precisely, the authors show that when $h=1$, common macroeconomic uncertainty shocks account for between $3.59 \%$ and $15.13 \%$ of the forecast error variance in industrial production, compared to $0.52 \%$ and $10.56 \%$ for $h=12$. For a review on the effects of maturity on uncertainty, see Bloom (2014).
} 
Figure 1 - Alternative measures of macroeconomic uncertainty

Panel A: Conditional variance US GDP growth
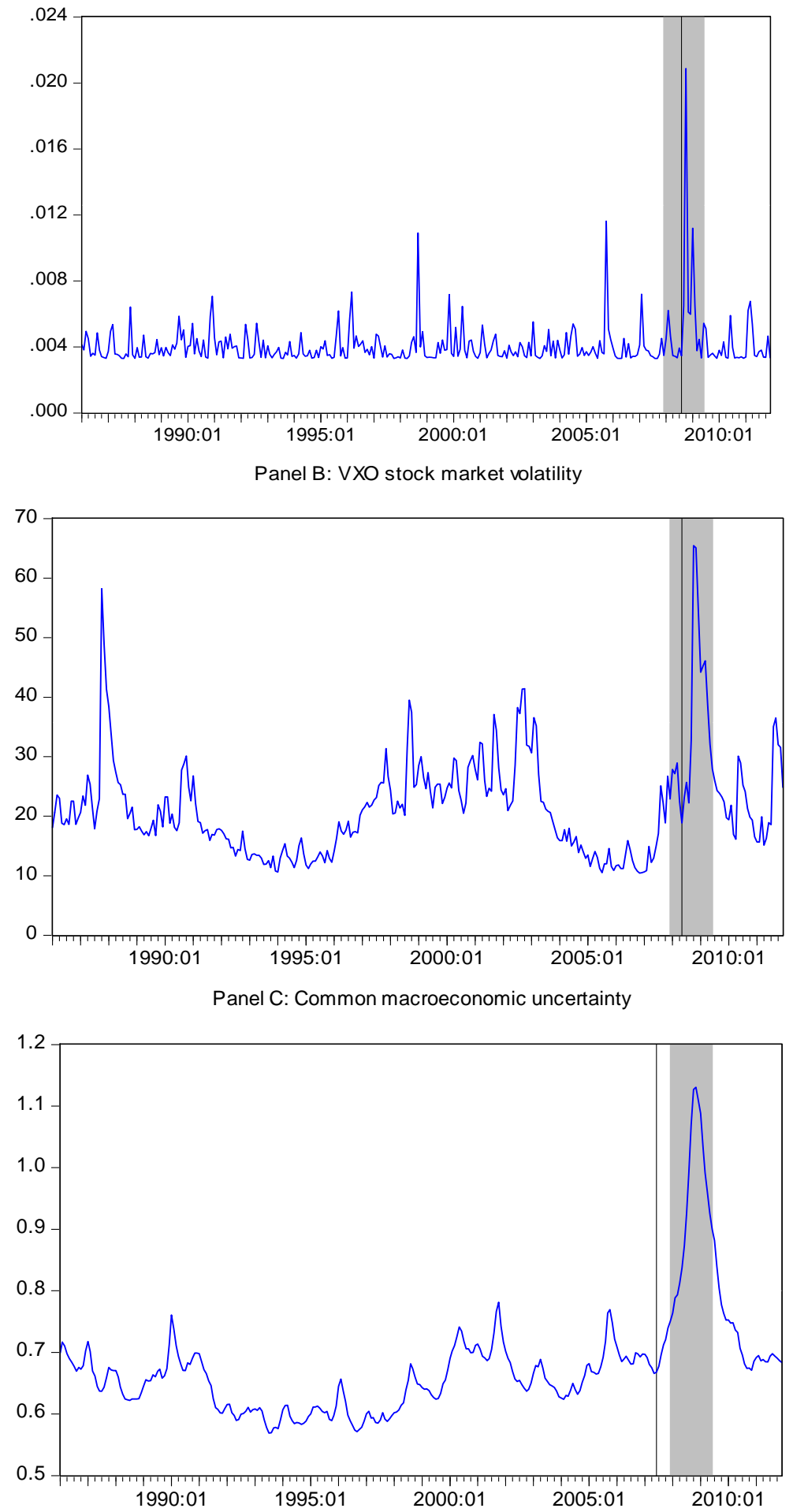
and short-run uncertainty can thus have no impact for long-run investment strategies. All in all, accounting for the effect of maturity when investigating the impact of uncertainty is thus of crucial importance.

\section{Data and model specification}

We consider a large dataset of 19 principal commodity markets, classified into four categories: energy, precious metals, agriculture, and industry. Related price series are monthly, starting in October 1978 for energy markets, February 1976 for precious metals markets, and February 1980 for agricultural and industrial markets. The period ends in December 2011 for all groups of commodities. All series are transformed into first-logarithmic differences (i.e., price returns), ${ }^{33}$ as described in Table 1 in Appendix A, which also provides data sources. Turning to data related to macroeconomic uncertainty measures for distinct maturities, they are freely available on Ludvigson's homepage. ${ }^{34}$

\subsection{Structural threshold VAR model}

To analyze whether uncertainty affects commodity prices' behavior depending on the level of uncertainty, we consider that uncertainty may be a nonlinear propagator of shocks across markets, captured by a structural threshold vector autoregressive model. ${ }^{35},{ }^{36}$ In addition to providing an intuitive way to capture the nonlinear effects of uncertainty on markets, the TVAR model has the advantage of endogenously identifying different uncertainty states. Indeed, according to this specification, observations can be divided, for example, into two states delimited by a threshold reached by uncertainty, with estimated coefficients that vary depending on the considered state (low- and high-uncertainty states). In other words, the TVAR specification allows uncertainty states to switch as a result of shocks to commodity markets. ${ }^{37}$

\footnotetext{
${ }^{33}$ The results of unit root tests are available upon request to the authors and show that all price return series are stationary at conventional statistical levels.

${ }^{34}$ http://www.econ.nyu.edu/user/ludvigsons/.

${ }^{35}$ See Balke (2000) for a detailed presentation of TVAR processes as well as Tong (2010) and Hansen (2011) for general developments on threshold models. Van Robays (2013) uses the TVAR methodology to examine uncertainty on the oil market.

${ }^{36}$ It is important to note that nonlinearities may arise in many different forms. So far, empirical papers on the energy prices-economic activity nexus have mainly focused on asymmetric specifications (see e.g. Hamilton, 1996, 2003; Davis and Haltiwanger, 2001; Kilian and Vigfusson, 2011a,b; Herrera et al., 2011; Venditti, 2013). Our main purpose in this paper is to investigate whether the effect of macroeconomic uncertainty on commodity price returns depends on the regime of uncertainty, justifying the use of a threshold specification. ${ }^{37}$ This characteristic is particularly relevant in our context because assuming strict exogeneity between macroeconomic uncertainty and the oil market might not be realistic (see below and Van Robays, 2013, among others).
} 
For each of our four groups of commodity markets, we consider a structural TVAR model of the form:

$$
Y_{t}=\mu_{1}+A^{1} Y_{t}+B^{1}(L) Y_{t-1}+\left(\mu_{2}+A^{2} Y_{t}+B^{2}(L) Y_{t-1}\right) I_{t}\left(c_{t-d} \geq \gamma\right)+u_{t}
$$

where $Y_{t}$ is a vector of endogenous variables containing both the price returns of all commodities belonging to the considered group (energy, precious metals, industry, and agriculture) and the measure of macroeconomic uncertainty, ${ }^{38} A^{1}$ and $A^{2}$ reflect the structural contemporaneous relationships in the two states, respectively, $B^{1}(L)$ and $B^{2}(L)$ are lag polynomial matrices, $\mu_{1}$ and $\mu_{2}$ are vectors of constants, and $u_{t}$ denotes the vector of orthogonalized error terms. $c_{t-d}$ is the $d$-lagged threshold variable, which is a function of uncertainty (this hypothesis is discussed and tested below, as well as the choice of the optimal value of $d) . \quad I_{t}\left(c_{t-d} \geq \gamma\right)$ is an indicator function that equals 1 when $c_{t-d} \geq \gamma$ and 0 otherwise, where $\gamma$ denotes the threshold uncertainty critical value that has to be endogenously estimated. In other words, two states are identified: the low-uncertainty state corresponding to a weak degree of uncertainty $\left(I_{t}()=0.\right)$ and the high-uncertainty state related to a high degree of uncertainty $\left(I_{t}()=1.\right)$. As shown by Equation (4), the coefficients of the TVAR model are allowed to change across states depending on the level of uncertainty. Given the common belief in the literature since the beginning of the 1970s about the endogenous nature of commodity prices with respect to macroeconomic aggregates, ${ }^{39}$ we follow Kilian and Vega (2011) and adopt a recursive structure ${ }^{40}$ in $A^{1}$ and $A^{2}$ based on a prespecified causal order (to orthogonalize the residuals), ordering commodity prices first and macroeconomic uncertainty last. ${ }^{41}$ With this specific ordering, the response of commodity prices to changes in macroeconomic uncertainty is assumed to occur with a delay, which is consistent with the findings of the empirical literature (see e.g. Kilian and Vega, 2011).

\footnotetext{
${ }^{38}$ We have four different equations, one equation per group of commodity prices: (i) energy: oil, gas, uncertainty proxy; (ii) precious metals: gold, silver, platinum, uncertainty proxy; (iii) agricultural: cocoa, cotton, corn, coffee, lumber, soybeans, sugar, wheat, uncertainty proxy; and (iv) industry: aluminium, copper, lead, nickel, tin, zinc, uncertainty proxy.

${ }^{39}$ See among others, Rotemberg and Woodford (1996); Davis and Haltiwanger (2001); Lee and Ni (2002); Leduc and Sill (2004); Blanchard and Gali (2007); Edelstein and Kilian (2007); Kilian and Park (2009).

${ }^{40} \mathrm{We}$ extend to the conditional variance the predeterminedness assumption of Kilian and Vega (2011) on the conditional mean.

${ }^{41}$ Results from this specification are those we present in the empirical part of the paper. However, our conclusions are robust to different ordering, i.e. macroeconomic uncertainty first and prices last. The latter specification assumes instantaneous feedback from macroeconomic aggregates to commodity prices, and has been much criticized in the literature (see Kilian and Vega, 2011).
} 
An essential step is to test for the existence of a threshold effect with respect to uncertainty. However, the testing procedure is not straightforward because under the null hypothesis of no threshold effect, the threshold value is not known a priori and has to be estimated. ${ }^{42}$ To test for a threshold effect, we rely on nonstandard inference and estimate the model by least squares for all possible threshold values. Conditionally to each possible threshold, we generate three Wald-type statistics using Hansen (1996)'s simulation method to test the null hypothesis of no difference between states: ${ }^{43}$ the maximum Wald statistic over all possible threshold values (sup-Wald), the average Wald statistic over all possible values (avg-Wald), and a function of the sum of exponential Wald statistics (exp-Wald). The estimated threshold values are those that maximize the log-determinant of the variancecovariance matrix of residuals.

\subsection{Endogeneity and strict exogeneity between macroeconomic and commodity prices}

As mentioned above, another complication when estimating TVAR models concerns the endogeneity issue. Endogeneity may come from the fact that the threshold variable (our uncertainty measure) is allowed to endogenously respond to commodity price shocks. One way to address this problem is to assume strict exogeneity between variables. However, as discussed by Van Robays (2013) among others, assuming strict exogeneity between oil prices (and commodity prices in general) and macroeconomic uncertainty is not realistic because it is well known that a strong relationship exists between the oil market and economic activity (see, e.g., Barksy and Kilian, 2002, 2004; Kilian, 2008a,b; Hamilton, 2009). Therefore, a common approach is to impose the threshold variable to switch across states with a delay. This implies that we only evaluate commodity price shocks that occur within a certain state. Another common assumption in the TVAR literature is to define the threshold variable as a moving average process that requires some persistence in the variation of the threshold variable before shocks cause the regime switching. To fully address the issue of endogeneity, we combine these two approaches in the present paper by considering a three-period moving average of our one-period-lagged threshold variable. ${ }^{44}$

\footnotetext{
${ }^{42}$ If the threshold value was known, it would be possible to simply test $\mu_{2}=A^{2}=B^{2}(L)=0$.

${ }^{43}$ Because the asymptotic distribution of Wald statistics is nonstandard, we indeed use Hansen (1996)'s bootstrap procedure to simulate the related distribution and conduct inference.

${ }^{44}$ Results (available upon request to the authors) are robust to different lag specifications.
} 


\section{Uncertainty transmission across states}

We now use the TVAR approach to apprehend the impact of macroeconomic uncertainty on commodity prices. We first present threshold test results and related comments. We then complement the analysis by conducting nonlinear impulse-response function (IRF) analysis under high- and low-uncertainty states to investigate whether the transmission of macroeconomic uncertainty shocks into commodity markets differs across states. Finally, we assess the influence of the considered maturity.

\subsection{Threshold test results}

Tables 2 to 5 in Appendix A report the three threshold test results for each group of commodity markets at different maturities together with the "percentage of high uncertainty" corresponding to the percentage of observations such that the threshold variable is above the estimated threshold critical value. ${ }^{45}$ Our main results can be summarized as follows.

First, the null hypothesis is always rejected in favor of the presence of threshold effects for each group of markets and the maturity considered. The TVAR specification is thus appropriate because it accounts for varying effects of uncertainty depending on the degree of uncertainty. Second, the estimated threshold values increase with the maturity, meaning that as $h$ increases, the switching mechanism between low- and high-uncertainty states is delayed. This finding reflects a different perception of the level of uncertainty as the horizon increases (see Bloom, 2014) and is also consistent with Jurado et al. (2014)'s conclusions, highlighting that the level of uncertainty tends to augment along with the maturity. Third, turning to the percentage of high uncertainty, the results deserve some detailed comments. Whatever the maturity considered, agricultural and industrial markets display the highest percentages, whereas energy and precious metals markets are characterized by similar lower values. Moreover, high-uncertainty percentage values are quite stable, regardless of the considered maturity for the latter two markets. Regarding precious metals, this result can be explained by their safe-haven role across all horizons during times of economic turmoil (see Bredin et al., 2014), making them an interesting tool to transfer short-run uncertainty to longer one. Concerning energy markets, the limited substitution effects at relatively short-term horizons may explain the stability of the high-uncertainty percentage values. Turning to agricultural markets, this sector is highly sensitive to the unexpected changes in economy (see Baumeister and Kilian, 2014), explaining why the high-uncertainty percentage value is higher at the short-run, one-month maturity. Finally, the observation that the

\footnotetext{
${ }^{45}$ Following Jurado et al. (2014), we retain three maturities corresponding to macroeconomic uncertainty at 1,3 , and 12 months, referring to short-, medium-, and long-run perceptions, respectively.
} 
percentage of high uncertainty increases with the maturity in the case of industrial markets results from the sensitivity of this sector to structural factors that are more at play in the long run. Indeed, to design proper R\&D investment strategies, firms usually have to focus on longer horizons. Fourth, the evolution of the percentage of high uncertainty according to the value of $h$ also provides useful information regarding the sensitivity of commodity markets to the level and variability of uncertainty. Indeed, as shown by Jurado et al. (2014), the level of uncertainty increases with $h$, whereas its variability is a decreasing function of $h$ because the forecast value tends to the unconditional mean as the forecast horizon tends to infinity. Consequently, the percentage of high uncertainty in agricultural markets seems to be more sensitive to the variability of uncertainty (short-run uncertainty), but for industrial markets, this percentage increases with $h$ and seems to be more sensitive to the level (long-run uncertainty).

Figure $1 \mathrm{~B}$ in Appendix $\mathrm{B}$ presents these findings in a more dynamic way by showing the evolution of our macroeconomic uncertainty measure at one month over the whole period together with the corresponding threshold value. For almost all markets, periods of high uncertainty coincide with episodes of heightened macroeconomic uncertainty, such as the 1981-82 and 2007-09 recessions. These figures also illustrate the relevance of our measure of uncertainty. As stressed above, we identify a few high-uncertainty episodes compared with studies that rely on standard volatility-type proxies, such as Bloom (2009) and Van Robays (2013). Consequently, most of the fluctuations attributed to uncertainty using popular proxies are in fact not associated with a broad-based movement in economic uncertainty. In other words, much of the variation in traditional uncertainty proxies is not driven by uncertainty itself, again highlighting the interest of our retained measure.

\subsection{Nonlinear impulse-response function analysis}

Figures $1 \mathrm{C}$ to $4 \mathrm{C}$ in Appendix C depict the impact of macroeconomic uncertainty for $h=1$ on each commodity price return series. As shown, four lines are displayed, corresponding to positive and negative nonlinear impulse response functions (IRFs) under high- and lowuncertainty states following a two-standard-deviation macroeconomic uncertainty shock. For almost all series and as expected, positive macroeconomic uncertainty shocks (i.e., increase in macroeconomic uncertainty) affect commodity price returns negatively on average, whereas negative shocks (i.e., decrease in macroeconomic uncertainty) impact price returns positively on average. This is a quite logical result, confirming that Jurado et al. (2014)'s macroeconomic uncertainty proxy is clearly countercyclical. Moreover, the IRF analysis puts forward asymmetric behavior. Indeed, the impact of macroeconomic uncertainty is generally stronger in high-uncertainty states compared with low-uncertainty states, 
with commodity price returns being more sensitive to events that lessen the predictability of macroeconomic variables. These findings illustrate the interest of the TVAR specification by showing that the impact of macroeconomic uncertainty on commodity markets depends on its intensity.

At a more detailed level, considering the cases of energy and precious metals, the responses of oil, gold, platinum, and silver markets are unequivocal because price returns strongly react to macroeconomic uncertainty shocks in high-uncertainty states (between 4\% to 7\% for oil, gold and platinum and approximately 10\% for silver). Moreover, though the responses to positive and negative shocks are quite persistent (eight months) and symmetric for oil and platinum, the responses of gold and, to a lesser extent, silver are more transient (approximately four months) and asymmetric. The safe-haven role of gold and silver markets during periods of economic downturn could be one plausible explanation about the rapid overshooting reaction of both prices. ${ }^{46}$ The main drivers of oil and platinum markets are sensitive to macroeconomic uncertainty shocks because they are strongly related to economic activity through industry purposes. A different pattern is observed for the gas market, for which the response to macroeconomic uncertainty shocks is more important in low-uncertainty states. The regional organization of this market may explain its relatively weak sensitivity to high macroeconomic uncertainty. Turning to the industrial and agricultural sectors, all industrial markets but the zinc follow quite similar patterns significantly reacting to uncertainty, as do agricultural markets with the exception of coffee-which is a highly volatile market-and, to a lesser extent, sugar and wheat.

\subsection{Does maturity matter?}

Examining the influence of maturity when investigating the impact of uncertainty on prices is of particular importance given the multiple channels and different effects at play at short, medium-, and long-run horizons. ${ }^{47}$ Understanding the maturity perception in assessing uncertainty is also of primary importance for commodity prices since maturity may capture different behaviors. For instance, short- and medium-run uncertainty may capture a kind of reallocation effect (Hamilton, 1988) since such maturities focus on current behaviors, while a long-run perception of uncertainty may be more related to Bernanke (1983)'s framework

\footnotetext{
${ }^{46}$ Recall that the proxy is countercyclical meaning that increases in uncertainty correspond to recessionary periods. Therefore, for gold and silver prices two effects seem to be at play: (i) macroeconomic uncertainty decreases the general price level since the economy is in recession, and (ii) after a certain delay, the safe-haven role of precious metals leads to rapid strong overshooting behaviors.

${ }^{47}$ See the Introduction and Section 2.4 for a discussion, and Bloom (2014) for a review.
} 
because it corresponds to horizons relevant to purchase and investment decisions. ${ }^{48}$ Our results in Section 4.1 give us a first insight about the static sensitivity of prices to maturity.

Turning now to the dynamic analysis, Figure 1D in Appendix D reports the average (per group of markets) cumulative responses of prices to positive high uncertainty two-standard deviations shocks at maturity $h$. As before, three values of $h$ are considered-namely, 1,3 and 12 months. The results are consistent with those of Section 4.1 revealing that maturity matters for some markets. Though the percentage of high uncertainty is quite stable across maturity for energy and precious metals markets, the responses of both groups to a positive shock are quite similar giving more importance to the short-run effect. While the impact of short-run uncertainty is clear for energy markets (in line with the close relationship that exists between energy and economic activity in the short run), the response of precious metals markets seems to be more sensitive to long-run uncertainty after a certain delay. ${ }^{49}$ The specific behavior of precious metals markets may come from the well-known safe-haven property transferring uncertainty at 1 month to longer horizons (12 months). For industrial markets the conclusion is more straightforward, uncertainty at longer maturity $(h=12)$ has a greater immediate impact on price returns, confirming the high sensitivity of such markets to structural factors and the reactiveness of industrial firms to horizons relevant to long-run investments. Regarding the agricultural sector, markets also appear to be more sensitive to long-run uncertainty, which is quite logical since agricultural firms may face longer horizons with respect to agricultural investment decisions. On the whole, the important point regarding the impact on commodity prices is not only the percentage of high uncertainty but also how shocks are incorporated into the system and, in turn, their implications for economic behaviors.

\section{Does macroeconomic uncertainty generate commodity uncertainty?}

To provide a complete description of the links between macroeconomic uncertainty and commodity markets, we go a step further and investigate how macroeconomic uncertainty can affect each commodity market uncertainty. To this end, we must define an uncertainty

\footnotetext{
${ }^{48}$ Recall that, by construction, the level and the variability of our proxy of uncertainty respectively increases and decreases with $h$. This property allows us to apprehend the sensitivity of commodity prices to both the level and the variability of uncertainty.

${ }^{49}$ Given the importance of the oil market in the literature, Figure 2D in Appendix D reports the specific response of the oil price to positive (left side) and negative (right side) macroeconomic shocks across maturity. As for the whole energy markets group, the oil price is more sensitive to short-run uncertainty after a positive shock. Looking at negative shocks (i.e. decrease in macroeconomic uncertainty), the response is quite symmetric to the positive one, highlighting the importance of short-run uncertainty.
} 
measure for each market and then assess the transmission mechanism of macroeconomic uncertainty to each specific commodity market uncertainty.

\subsection{Measuring commodity market uncertainty}

Let us first consider the determination of the commodity market uncertainty proxy. We rely on Equation (1) and proceed in two steps. In a first step, we use the previously estimated TVAR model to generate the $h$-period-ahead forecast of the considered price return series, accounting for the information about macroeconomic uncertainty. Let $E\left[y_{t+h} / J_{t}, u_{t}^{u}\right]$ be the obtained forecast, where $y$ is the considered commodity price return series, $J_{t}$ the information set available at time $t$, and $u_{t}^{u}$ the macroeconomic uncertainty shock at time $t$. As seen, our forecast value accounts for information about macroeconomic uncertainty. Given this forecast, we define in a second step the $h$-period-ahead forecast error as the difference between $y_{t+h}$ and $E\left[y_{t+h} / J_{t}, u_{t}^{u}\right]$, the forecast that accounts for information about macroeconomic uncertainty. The underlying idea is that a way to understand the transmission mechanism of macroeconomic uncertainty to commodity markets is to assess how the forecast of our considered variable changes if we add information about macroeconomic uncertainty. The commodity market uncertainty measure is then given by the volatility of this forecast error.

To account for the volatility-clustering phenomenon, which is a typical feature of commodity markets, we rely on time-varying volatility specifications and consider the moving average stochastic volatility model developed by Chan and Jeliazkov (2009) and Chan and Hsiao (2013) given by: ${ }^{50}$

$$
x_{t}=\lambda+v_{t}
$$

where $x_{t}$ denotes the forecast error, i.e., the difference between the forecast of $y$ that does not account for information about macroeconomic uncertainty and the forecast that accounts for such information. The error term $v_{t}$ is assumed to be serially dependent, following a $\mathrm{MA}(q)$ process of the form:

$$
v_{t}=\varepsilon_{t}+\psi_{1} \varepsilon_{t-1}+\ldots+\psi_{q} \varepsilon_{t-q}
$$

\footnotetext{
${ }^{50}$ For robustness checks, the GARCH, standard stochastic, and heavy-tailed stochastic volatility models have also been considered to estimate the volatility of forecast errors. The corresponding results, available upon request to the authors, are quite similar between models.
} 


$$
h_{t}=\lambda_{h}+\phi_{h}\left(h_{t-1}-\lambda_{h}\right)+\zeta_{t}
$$

where $\varepsilon_{t} \sim N\left(0, e^{h_{t}}\right)$ and $\zeta_{t} \sim N\left(0, \sigma_{h}^{2}\right)$ are independent of each other, $\varepsilon_{0}=\varepsilon_{-1}=$ $\ldots=\varepsilon_{-q+1}=0$, and the roots of the polynomial associated with the MA coefficients $\psi=\left(\psi_{1}, \ldots, \psi_{q}\right)^{\prime}$ are assumed to be outside the unit circle. $h_{t}$ is the log-volatility evolving as a stationary $A R(1)$ process. Following Chan and Hsiao (2013), under the moving average extension, the conditional variance of the series $x_{t}$ is given by:

$$
V\left(x_{t} \mid \lambda, \psi, h\right)=e^{h_{t}}+\psi_{1}^{2} e^{h_{t}-1}+\ldots+\psi_{q}^{2} e^{h_{t}-q}
$$

This specification allows us to capture two nonlinear channels of macroeconomic uncertainty: (i) the one coming from the moving average of the $q+1$ most recent variances $e^{h_{t}}+\ldots+e^{h_{t}-q}$, and (ii) the other from the AR(1) log-volatility stationary process given by Equation (7).

Given the challenge of estimating this kind of nonlinear model due to high-dimensional and nonstandard data- with the conditional density of the states being non-Gaussiana Bayesian estimation using Markov chain Monte Carlo methods is hardly tractable. We follow Chan and Hsiao (2013) and estimate the conditional variance of forecast errors by band-matrix algorithms instead of using conventional methods based on the Kalman filter ${ }^{51}$

\subsection{Transmission of macroeconomic uncertainty to commodity market uncertainty}

Figures $1 \mathrm{E}$ to $4 \mathrm{E}$ in Appendix $\mathrm{E}$ depict the evolution of uncertainty in commodity markets for 1 month (blue line), ${ }^{52}$ together with the evolution of corresponding prices (black line) and volatility (green line). The horizontal bar corresponds to 1.65 standard deviation above the mean of each commodity-related uncertainty series. When uncertainty in commodity markets exceeds the horizontal bar, this refers to episodes of heightened uncertainty for the considered price return series. When commodity price uncertainty coincides with the vertical gray bands, it indicates a potential transfer from macroeconomic to commodity market

\footnotetext{
${ }^{51}$ See Chan and Jeliazkov (2009) and Chan and Hsiao (2013) for more details. The Matlab code used to estimate the moving average stochastic volatility model is freely available from the website of Joshua Chan. We obtain 20000 draws from the posterior distribution using the Gibbs sampler after a burn-in period of 1000 . ${ }^{52}$ We focus on short-run uncertainty $(h=1)$ because the effects have been largely documented both theoretically and empirically in the literature (see Bloom, 2014, for a review). For the sake of completeness, we have also estimated uncertainty at longer horizons, namely, 3 and 12 months. The corresponding figures are available upon request to the authors.
} 
uncertainty (with both uncertainty episodes occurring in the same period). ${ }^{53}$ Otherwise, uncertainty is attributable to the own characteristics of the considered raw materials market.

Consider first the case of energy markets. As shown in Figure 1E (Appendix E), the sensitivity of oil price uncertainty to macroeconomic uncertainty differs depending on the retained period, highlighting that oil shocks do not all follow the same pattern. For example, the period that just follows the invasion of Kuwait in 1990, the Afghan war in 2001, and the Iraq War in 2002-03 are episodes characterized by sharp spikes in oil prices. The Iran-Iraq war in 1980 and the 1999 OPEC meeting are, in contrast, associated with small price movements. As stressed by Barsky and Kilian (2004), a simplistic view should be that major war episodes cause price uncertainty to increase through a rise in precautionary demand for oil. ${ }^{54}$ However, among all episodes of important fluctuations in oil prices, only two seem to be accompanied by uncertainty: ${ }^{55}$ (i) the 2007-09 recession, and (ii) the 1984-86 period. During the 2007-09 recession, oil price uncertainty is indeed very sensitive to macroeconomic uncertainty, a result that is not surprising given the well-known relationship that exists between economic activity and the oil market. ${ }^{56}$ This episode of high oil price uncertainty is accompanied by the biggest oil price spike in the postwar experience and result from various macroeconomic factors. A common explanation lies in the global economic growth starting in 2003, as illustrated by the increase in real gross world product combined with the stagnant oil production from Saudi Arabia from 2005 to $2007 .{ }^{57}$ Whatever the origin of price surges, this period of macroeconomic uncertainty is reflected in oil market uncertainty by an unprecedented oil price increase. The 1984-86 period is also characterized by heightened oil price uncertainty, but it does not coincide with macroeconomic uncertainty. This episode seems to be related to the conjunction of two events: (i) the production shutdown in Saudi Arabia between 1981 and 1985, which caused a strong price decrease; ${ }^{58}$ and to

\footnotetext{
${ }^{53}$ Recall that the gray bands correspond to episodes of important macroeconomic uncertainty: the months surrounding the 1973-74 and 1981-82 recessions and the 2007-09 great recession.

${ }^{54}$ According to this view, the demand for oil should shift because consumers feel that the likelihood of a major oil supply interruption has increased (see Barsky and Kilian, 2004). Such view, suggesting that major increases in the price of oil tend to be driven by exogenous events in the Middle East, has been the conventional wisdom until recently.

${ }^{55}$ In Section 5.2 we precisely investigate what types of shocks tend to increase oil price uncertainty.

${ }^{56}$ See Barksy and Kilian (2002, 2004), Kilian (2008a,b, 2009), Kilian and Murphy (2012, 2014), and Kilian and Hicks (2013) to name a few.

${ }^{57}$ According to the U.S. Energy Information Administration, the total Saudi Arabia crude oil production significantly decreases from 9,550.136 thousand barrels per day in 2005 to 8,721.5068 thousand barrels per day in 2007.

${ }^{58} \mathrm{At}$ the beginning of the 1980s, the strategy of Saudi Arabia to shut down production (compensating higher oil production elsewhere in the world) was initiated to prevent an oil price decline, without success. Saudi Arabia finally decided to ramp production back up in 1986, causing an oil shock from $\$ 27 /$ barrel in 1985 to $\$ 12 /$ barrel in 1986 (see Kilian and Murphy, 2014).
} 
a lesser extent (ii) the OPEC collapse in 1986. On the whole, our results are in line with the literature that has recently stressed the limited impact of exogenous events on oil price fluctuations. Turning to gas, the conclusion is somewhat different given the well-known regional organization of the market which may exempt the price from several international shocks. Results indeed show that macroeconomic uncertainty does not generate uncertainty in the gas market. In particular, we do not observe heightened movements during the 2007-09 recession confirming that the gas price should be more influenced by microeconomic events related to industrial considerations. Some exceptions can be highlighted in 1996, 2001, and 2005, where the gas market experienced short-lived periods of price increase and strong volatility. These events are however more related to extreme climatic events (unusually cold weather in 1996 and the Katrina/Rita hurricanes in 2005) and do not lead to episodes of extreme uncertainty (see Kilian, 2010).

As discussed by Jurado et al. (2014) and confirmed by our previous analysis, macroeconomic uncertainty is strongly countercyclical, ${ }^{59}$ roughly doubling in importance during recessions. Given the role of precious metals (especially gold and silver) as safe havens and hedging instruments during financial and macroeconomic turmoils, their prices are often countercyclical as well (see Christie-David et al., 2000; Roache and Rossi, 2009; Creti et al., 2013) and should increase in periods of macroeconomic uncertainty, at least in the short run. Regarding the 2007-09 recession, it seems (Figures 2E in Appendix E) that increases in gold and silver prices were largely anticipated because the related uncertainty remained relatively low. In other words, macroeconomic uncertainty did not spread to precious metals markets. This finding confirms the safe-heaven role of gold and silver given that macroeconomic uncertainty surrounding the global crisis pushed up their prices, but did not induce uncertainty in their respective markets. However, at the beginning of the 1980s, the high-uncertainty period associated with gold and silver prices coincided with the 1981-82 recession. The gold market, which is often used as a hedging instrument against inflation pressures, experienced huge movements in 1980 due to the continued stop-and-go monetary policy of the Fed raising its rate to $20 \%$, then lowering it to $8 \%$, and augmenting it again to $20 \% .{ }^{60}$ Uncertainty in the gold price was further amplified in 1981, when Reagan decided to establish a Gold Commission to reject the return of the United States to the gold standard system, leading the Fed to implement a contractionary policy that reduced inflation but favored recession. Other events likely to influence gold prices, such as the bombing of the Twin Towers in September 2001 or the launch of the Electronic Trading Funds (ETF's) in the gold market in 2003, do not lead to price uncertainty. The silver

\footnotetext{
${ }^{59}$ One reason is that exogenous shocks that often cause recessions-such as wars or financial panics—also directly increase uncertainty (see Bloom, 2014).

${ }^{60}$ On January 21,1980 , the gold price reached a record level of $\$ 850$.
} 
price displays a similar behavior as the gold price, but uncertainty appears to be amplified, particularly at the beginning of the 1980s. Among the several causes of silver price movements, various political events-including the continuous U.S. hostage crisis in Iran and the Soviet invasion of Afghanistan-motivated an increasing demand for silver, keeping the price at relatively high levels in 1980 and leading to high uncertainty in the silver market. Another well-known episode affecting the silver price evolution around this period is the Hunt Brothers' story from the 1970s to the end of the 1980s. ${ }^{61}$ The worldwide 198182 recession strengthened this period of uncertainty. The propagation mechanism at play during this recessionary episode was intrinsically linked to precious metals markets through inflation targeting and the Fed interest rate policy, contrary to the recent financial crisis. Unlike gold, which is mainly used in jewelry and as a store of value, platinum is a crucial resource in industry ${ }^{62}$ _automotive industry, for instance, represented approximately $60 \%$ of the total demand for platinum in 2007 (see Johnson Matthey Plc., 2008). Its price is thus strongly related to economic activity, and episodes of high macroeconomic uncertainty tend to affect platinum price uncertainty, as it was the case during the 2007-09 recession.

As the oil price, most of industrial markets are strongly connected to global economic activity. This important link is evidenced by the transfer of uncertainty from the macroeconomic level to commodity prices, especially for copper, lead, nickel and tin prices (see Figures 3E in Appendix E). For instance, because copper is primarily employed for industrial purposes $^{63}$ (such as massive construction projects, infrastructure renewal, and telecommunication modifications), it is usually strongly related to global economic activity, and its price is often used as an indicator of global development. Therefore, the 2007-09 period of macroeconomic uncertainty is closely related to copper price uncertainty, as shown in Figure 3E. Similar patterns are observed for the other industrial markets, which are also strongly related to global economic conditions.

The transfer of macroeconomic uncertainty to agricultural and food prices uncertainty is

\footnotetext{
${ }^{61}$ At the beginning of the 1970s, the Hunt Brothers began accumulating large amounts of silver to hedge against oil investment, totaling almost the global market by 1979 (with an estimated holdings of the one third of the entire silver world supply). This accumulation rose the price of silver from $\$ 11$ per ounce at the end of 1979 to $\$ 50$ per ounce in January 1980 . In response to this speculative accumulation, the COMEX adopted on January 7, 1980 the "Silver Rule 7" placing heavy restrictions on the purchase of this commodity. Three months after (on March 27, 1980), the silver price collapsed to below $\$ 11$ per ounce. This event is known as the "Silver Thursday".

${ }^{62}$ In addition, platinum plays a key role in the production of various chemicals, silicones, computer hard drives, and flat-panel display glasses.

${ }^{63}$ Over the past century, the demand for refined copper has increased from 500,000 metric tons to over 19 million metric tons.
} 
of primary importance given the strong economical, political and social implications for both developing and developed countries. The increase in agricultural commodity prices since the mid-2000s has attracted particular attention among policymakers with regard to a global food shortage and inflationary pressures. ${ }^{64}$ Though a popular perception is that higher agricultural and food prices have been associated in recent years-especially during the 2007-09 period — with oil price surges, this general statement has been recently contradicted by Baumeister and Kilian (2014), who argue that agricultural and food price increases should not be interpreted as the causal effect of higher oil prices, but are rather the result of unexpected changes in demand associated with shifts in global real economic activity. Our findings (Figure 4E in Appendix E) confirm this interpretation, especially for corn, soybeans and wheat, for which price uncertainty occurs during the most striking episodes of macroeconomic uncertainty. Unexpected shifts in global economic activity would therefore be the main cause of uncertainty in agricultural prices during the 2007-09 recession. Periods for which agricultural price uncertainty is not related to macroeconomic uncertainty differ depending on the market. For instance, the most salient episode of coffee price uncertainty appears during 1994-97, when the price started a brief recovery after an intense Brazilian frost episode in 1994, which reduced Brazil's coffee exports. In 1989, the coffee price experienced a volatility spike after the end of the coffee agreement, but this episode did not lead to uncertainty because it was largely anticipated. Another example is the cotton market, which is characterized by a strong uncertainty episode that occurred in 2011, with a huge unanticipated price increase that could be explained by a constellation of events such as gradually tightening stocks, an unexpected freeze in China's cotton producing areas, historic floods in Pakistan and a ban on exports from India.

Overall, though the results are obviously somewhat heterogeneous across markets, the recent 2007-09 recession generated an unprecedented episode of uncertainty in the price of numerous commodities, particularly oil, platinum, various agricultural commodities and, especially, all industrial raw materials. The main exception concerns uncertainty related to gold and silver prices, a fact that can be explained by their roles as safe havens and hedging instruments. An additional result is that, as clearly shown by Figures $1 \mathrm{E}$ to $4 \mathrm{E}$ in Appendix E, uncertainty episodes are not necessarily accompanied by high volatility in commodity prices. This major finding illustrates the interest of our retained measure of uncertainty, underlining that uncertainty is more related to predictability than to volatility. The relevance of the predictability-based approach could be explained by some specific properties of the commodity markets. In particular, these markets are known to be characterized by a low

\footnotetext{
${ }^{64}$ As documented by Baumeister and Kilian (2014), in the Monday 23, 2007 edition, the Financial Times reported that "retail food prices are heading for their biggest annual increase in as much as 30 years, raising fears that the world faces an unprecedented period of food price inflation".
} 
elastic demand together with a strong inertial supply, making any unexpected adjustment difficult and costly.

\subsection{Historical decomposition analysis}

To assess the contribution of macroeconomic uncertainty to commodity prices uncertainty, we perform a historical decomposition analysis of each commodity market uncertainty with respect to macroeconomic uncertainty. Based on the estimation of VAR models, ${ }^{65}$ Figure $1 F$ in Appendix F reports the historical decomposition associated with oil and copper prices uncertainty. ${ }^{66}$ Results in Appendix F confirm those of the previous section. Indeed, looking at the crude oil market we find a strong proportion of macroeconomic uncertainty in oil price uncertainty during the recent 2007-09 financial crisis (around 35\% of oil price uncertainty is explained by macroeconomic uncertainty during this period). Recalling that our proxy of macroeconomic uncertainty is demand-driven, these conclusions are in line with the literature. During the 1986-87 episode, oil price uncertainty is not explained by macroeconomic uncertainty and the proportion of macroeconomic uncertainty appears to be negative. This suggests that other shocks not related to economic activity have been at play during this period. Turning to the copper price, we also find a transfer from macroeconomic uncertainty to price uncertainty, the share of macroeconomic uncertainty being around $12 \%$ during the recent financial turmoil. Overall, these results show that a significant component of price uncertainty can be explained by macroeconomic uncertainty. A key finding is that the recent oil price movements in 2005-08 associated with a rise in oil price uncertainty appear to be mainly the consequence of macroeconomic uncertainty, confirming the endogeneity of the oil price with respect to economic activity (i.e. the demand-driven characteristic). ${ }^{67}$

\subsection{Distinguishing between different types of shocks: the special case of oil}

As stressed above, macroeconomic uncertainty contributes to a large extent to price uncertainty. This result is of primary importance, particularly for the oil market since it shows that oil price uncertainty during the 2005-08 period can be partly explained by macroeconomic uncertainty. ${ }^{68}$ Besides, as stressed by the literature on oil prices, four types of

\footnotetext{
${ }^{65}$ The lag order of the VAR specification is 3, as selected by usual information criteria.

${ }^{66}$ Due to space constraints, we only report the results for oil and copper, two series that are strongly related to the macroeconomic context. The results for the other series, available upon request to the authors, show that the contribution of macroeconomic uncertainty to commodity price uncertainty is somewhat heterogeneous between markets.

${ }^{67}$ See Kilian (2008a, 2009), and Kilian and Murphy (2012, 2014) among others.

${ }^{68}$ Due to space constraints and given the key importance of oil for the global economy, we focus our discussion on this commodity.
} 
shocks can be distinguished: ${ }^{69}$ (i) shocks to the flow supply of oil, (ii) shocks to the flow demand for crude oil reflecting the state of the global business cycle, (iii) shocks to the speculative demand for oil stocks above the ground, and (iv) other idiosyncratic oil demand shocks. These different shocks may also be reflected in oil price uncertainty movements. Specifically, we aim here at investigating which type of shock contributes the most to oil price uncertainty.

As it is common in the literature, we proxy the flow supply in two ways: by the data on Saudi Arabia crude oil production, and by the global crude oil production-both series being from the Energy Information Agency (EIA). ${ }^{70}$ Our measure of fluctuations in global real activity is the dry cargo shipping rate index developed by Kilian (2009). Finally, turning to the speculative component of the oil demand, we rely on data for the U.S. crude oil inventories provided by the EIA. ${ }^{71}$ Figure $1 G$ in Appendix $G$ allows us to assess the quantitative importance of each type of shock (supply, demand, and speculation) on oil price uncertainty. Results show that the contribution of each shock to price uncertainty varies depending on the period, and that the nature of the shock matters in explaining oil price uncertainty. For instance, while Kilian (2009) identified the invasion of Kuwait in $1990^{72}$ and the Iraq War in $2002-03^{73}$ as episodes of surges in speculative demand for oil responsible for sharp price increases, we find that these events are not associated with important oil price uncertainty. More importantly, the contribution of the speculative shocks appears to be very limited or even negative compared to the contribution of flow supply (around 17\%) and flow demand (4\%) shocks in 1990.

Several events in the oil market history have appeared during the period 1986-87. The two

\footnotetext{
${ }^{69}$ See Kilian (2009), Baumeister and Peersman (2013), and Kilian and Murphy (2012).

${ }^{70}$ We only report results with Saudi Arabia crude oil production because they are more significant. Results from the global crude oil production are available upon request to the authors.

${ }^{71}$ As Kilian and Murphy (2014), we scaled the data on crude oil inventories by the ratio of OECD petroleum stocks over U.S. petroleum stocks for each time period. Note that given the imperfection of crude oil inventories data, Kilian and Lee (2014) also consider an alternative proxy compiled by the Energy Intelligence Group (EIG) providing detailed amounts of crude oil inventories by region, as well as oil at sea and oil in transit. They find that both proxies yield similar results.

${ }^{72}$ Hamilton (2009) rejected the hypothesis that shifts in speculative demand were behind the sharp increase in the crude oil price in 1990. Rather, he suggested that the price increase was the consequence of oil supply shocks. More recently, Kilian and Murphy (2014) found that the oil price increase was represented by two shocks occurring simultaneously: an unexpected flow supply disruption and an unexpected increase in speculative demand.

${ }^{73}$ Two effects on the oil price are at play during this period: a positive speculative demand shock due to the Iraq War in 2002-03, and a negative flow supply shock due to the Venezuelan crisis (see Kilian and Murphy, 2014, for a discussion).
} 
most important are the decision of Saudi Arabia to shut down the crude oil production to prop up the price of oil, and the OPEC collapse. While the latter is known to have limited impact on the crude oil price (see Barsky and Kilian, 2004), the former created a major positive shock to the flow supply droving down the price of oil. As we have seen, this period has lead to an important movement in oil price uncertainty. Figure $1 \mathrm{G}$ in Appendix $\mathrm{G}$ shows that this event is mainly supply-driven: around $18 \%$ of oil price uncertainty is explained by the shut down of Saudi Arabia crude oil production against less than $4 \%$ by the flow demand.

The most interesting episode over the last decades is obviously the unprecedented price surge after 2003 and, in particular, in 2007-08, which led to the most heightened period of oil price uncertainty. According to a popular view, this price increase was the consequence of speculative behaviors on the market (i.e. growing financialization of oil futures markets) and could not be explained by changes in economic fundamentals (see Fattouh et al., 2013, for a discussion). The standard interpretation is that oil traders in spot markets buy crude oil now and store it in anticipation of higher future oil prices. On the contrary, the recent literature supports the conclusion that the surge in the oil price during this period was mainly caused by shifts in the flow demand driven by the global business cycle (see Kilian, 2009; and Kilian and Hicks, 2013). Our findings corroborate this view that oil price uncertainty has been primarily driven by global macroeconomic conditions. Indeed, as shown in Figure 1G, the contribution of speculative demand to price uncertainty is very small (around $5 \%$ ) compared to the proportion of the flow demand from the global business cycle in 2008 (around $40 \%)$. An alternative view regarding speculation is that OPEC held back its production by using oil below ground in anticipation of higher oil prices. As discussed by Kilian and Murphy (2014), this behavior would be classified as a negative oil supply shock. Our results provide no evidence that such negative oil supply shocks have significantly contributed to oil price uncertainty, contrary to demand shocks.

Finally, looking at Figure 2G in Appendix G, which reports the simultaneous contribution of each shock (flow demand, flow supply, speculative demand, and macroeconomic uncertainty) to oil price uncertainty, we find that the 2007-08 period of heightened oil price uncertainty is mainly the consequence of shocks coming from the global business cycle and macroeconomic uncertainty. 


\section{Robustness checks}

\subsection{Volatility-based vs. predictability-based uncertainty measure}

To confirm the relevance of our predictability-based measure in the case of commodity markets, we assess the robustness of our findings to the choice of the proxy retained for uncertainty. As stressed above, uncertainty is an abstract concept that may have different meanings. Indeed, according to behavioral theories, it reflects a psychological state about possible futures, ${ }^{74}$ but it is also a broad concept linked to macro or micro phenomena (like GDP growth or the growth rate of firms among others). ${ }^{75}$ Whatever the considered definition, there is no perfect measure of uncertainty but instead a broad range of proxies. As described in Section 2, several studies have used stock market volatility as a proxy for uncertainty. ${ }^{76}$ In an influential paper, Bloom (2009) proposes a popular measure of uncertainty based on the VXO index, constructed by the Chicago Board of Options Exchange from the prices of options contracts written on the S\&P 100 index. He identifies 17 uncertainty dates, whereas Jurado et al. (2014) report far fewer uncertainty episodes, suggesting that variability in stock markets is much more related to volatility than to uncertainty affecting the whole economy. ${ }^{77}$ Therefore, comparing these two approaches allows us to compare both measures of uncertainty, namely the volatility-based and predictability-based proxies. Theoretically, each measure relies on different econometric concepts: the former approach approximates uncertainty by conditional volatility, while the latter requires to remove the forecastable component of the series before computing its conditional volatility. ${ }^{78}$ In other words, the predictability-based proxy distinguishes uncertainty in a series and its conditional volatility, while the volatility-based measure does not. As an illustrative purpose, Figure 2 reports the VXO index of Bloom (2009) and the macroeconomic uncertainty proxy $(h=1)$ introduced by Jurado et al. (2014) in standardized units. As shown, the predictability-based proxy allows us to identify only three episodes of uncertainty, which is far fewer than the 17 uncertainty dates detected using Bloom (2009)'s measure.

Figure $1 \mathrm{H}$ in Appendix $\mathrm{H}$ reports the response of commodity markets (for oil, gold, copper and cotton prices) following a positive two-standard-deviation $\mathrm{VXO}$ index and macroeco-

\footnotetext{
${ }^{74}$ In many behavioral theories, psychological uncertainty is assumed to be an important mediator of human in situations with unknown outcomes (see Windschitl and Wells, 1996).

${ }^{75}$ See Bloom (2014) for more details.

${ }^{76}$ See e.g. Romer (1990), Leahy and Whited (1996), Hassler (2001), Greasley and Madsen (2006), Bloom et al. (2007), Gilchrist et al. (2010), and Basu and Bundick (2011).

${ }^{77}$ See Jurado et al. (2014) for more details.

${ }^{78}$ See Section 2.
} 
Figure 2 - Bloom (2009)'s index vs. Jurado et al. (2014)'s measure for uncertainty

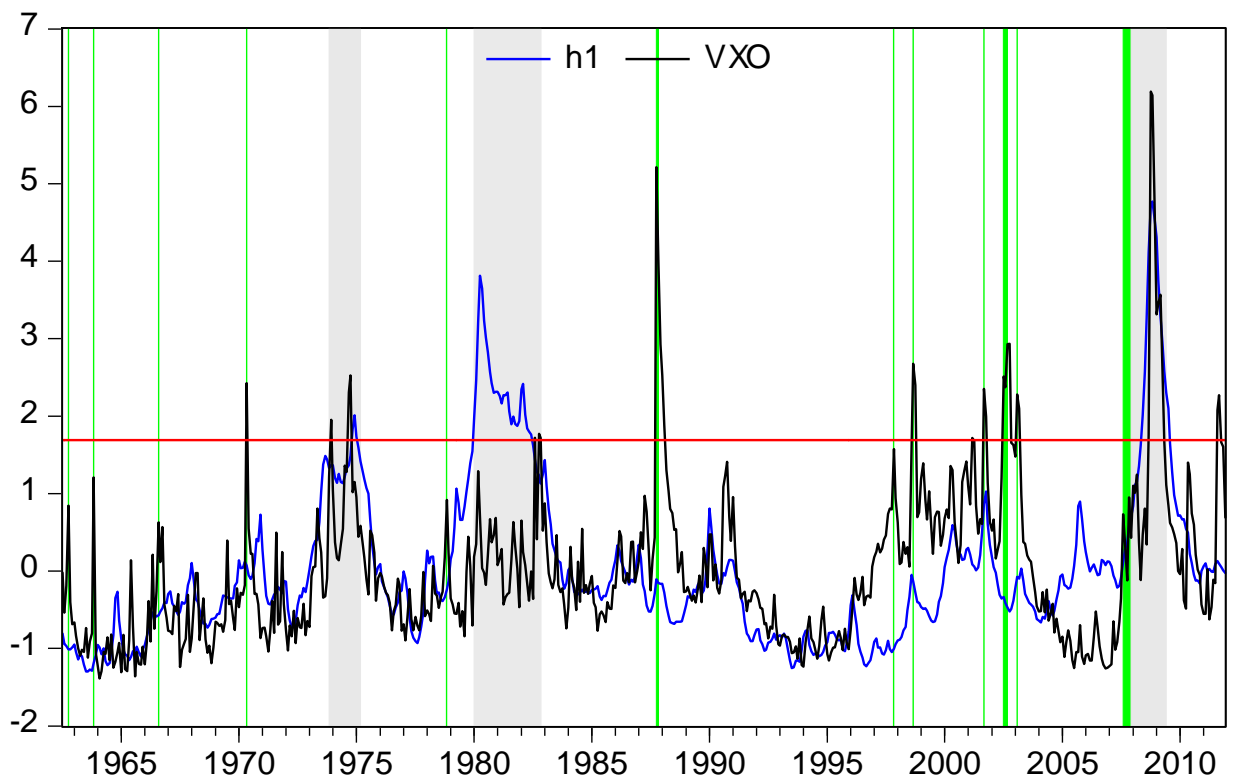

Note: This figure reports the VXO index (Bloom, 2009) and the h1 macroeconomic uncertainty (Jurado et al., 2014) in standardized units. The horizontal line is the 1.65 standard deviation above the unconditional mean of Jurado et al. (2014)'s proxy. The vertical lines are the uncertainty dates: Bloom (2009) is in green and Jurado et al. (2014) is in gray.

nomic uncertainty shocks in the high-uncertainty state. ${ }^{79}, 80$ In both cases, the level of oil and cotton prices is reduced following the shock, leading to similar conclusions whatever the retained proxy for uncertainty. The pattern is quite different for the other markets. Indeed, the response of gold and copper prices following a $V X O$ index shock is very low compared to that obtained with the macroeconomic uncertainty proxy. This particularity has also been noted by Jurado et al. (2014) regarding the response of production and employment, finding that the magnitude is larger when the shock comes from macroeconomic uncertainty at 1 month rather than from the $\mathrm{VXO}$ index. Moreover, macroeconomic uncertainty shocks generate a less significant "volatility overshoot" in commodity prices than the VXO index (with the exception of the cotton price). While the effect of macroeconomic uncertainty on commodity prices (especially for oil and copper prices) is more protracted (around 7 months), the response of prices after the VXO index shock is more transient (around 4 months for oil prices). This result further confirms that the macroeconomic uncertainty

\footnotetext{
${ }^{79}$ Due to space constraints, we only report the results for one series per group of commodities, and focus on positive shocks (i.e., increase in uncertainty) in the high-uncertainty regime. Complete results are available upon request to the authors.

${ }^{80}$ Following Bloom (2009), we include the log of the S\&P500 stock market index as the first variable in the VAR estimations to ensure the impact of stock market levels is already controlled for when looking at the effect of volatility shocks. Results are robust to alternative ordering.
} 
proxy is more persistent compared to popular volatility-based uncertainty proxies.

To complete our comparison, we follow the same procedure as in Section 5, and investigate how volatility-based uncertainty linked to the $\mathrm{VXO}$ index can generate commodity uncertainty. Figure $2 \mathrm{H}$ in Appendix $\mathrm{H}$ reports the evolution of commodity uncertainty for oil, gold, copper, and cotton prices for both the $\mathrm{VXO}$ and macroeconomic uncertainty proxies at 1 month $(h=1)$. When uncertainty in commodity markets exceeds the horizontal bar, this refers to episodes of heightened uncertainty for the considered price return series. When commodity uncertainty coincides with vertical bands, it indicates that uncertainty episodes occur at the same period than macroeconomic uncertainty (green bands for the VXO-based uncertainty measure and gray bands for our macroeconomic uncertainty proxy). As shown in Figure $2 \mathrm{H}$, both proxies generate quite similar commodity uncertainty dynamics. An interesting result concerns the case of the oil market for which commodity uncertainty is found to be more pronounced during the recent crisis using our retained macroeconomic uncertainty measure than with the VXO-based uncertainty measure. This is in line with our previous results showing that uncertainty episodes are not necessarily accompanied by high volatility in commodity prices. Moreover, macroeconomic uncertainty rightly affects the gold market during the 1981-82 recession, a characteristic that we identify using our predictability-based measure but not with Bloom (2009)'s proxy. On the whole, these findings illustrate the robustness of our conclusions to the retained proxy of uncertainty, and highlight the relevance of our measure in linking uncertainty to predictability rather than to volatility.

\subsection{Robustness of our proxy of oil price uncertainty}

An important query regarding our results in Section 5 refers to the robustness of our proxy of commodity price uncertainty. This question is of primary importance since, as discussed in the literature, ${ }^{81}$ one reason why previous studies do not find plausible empirical evidence of oil price uncertainty impact on GDP lies in the choice of an appropriate measure of uncertainty.

Theoretically, our approach implicitly assumes that oil price uncertainty (and commodity price uncertainty in general) is endogenous with respect to macroeconomic activity. As discussed in Section 2, this debate regarding the endogenous/exogenous nature of oil prices is of primary importance since it conditions the framework used to investigate the economy-oil

\footnotetext{
${ }^{81}$ See Kilian and Vigfusson (2011a) for a discussion.
} 
Figure 3 - Alternative measures of oil price uncertainty
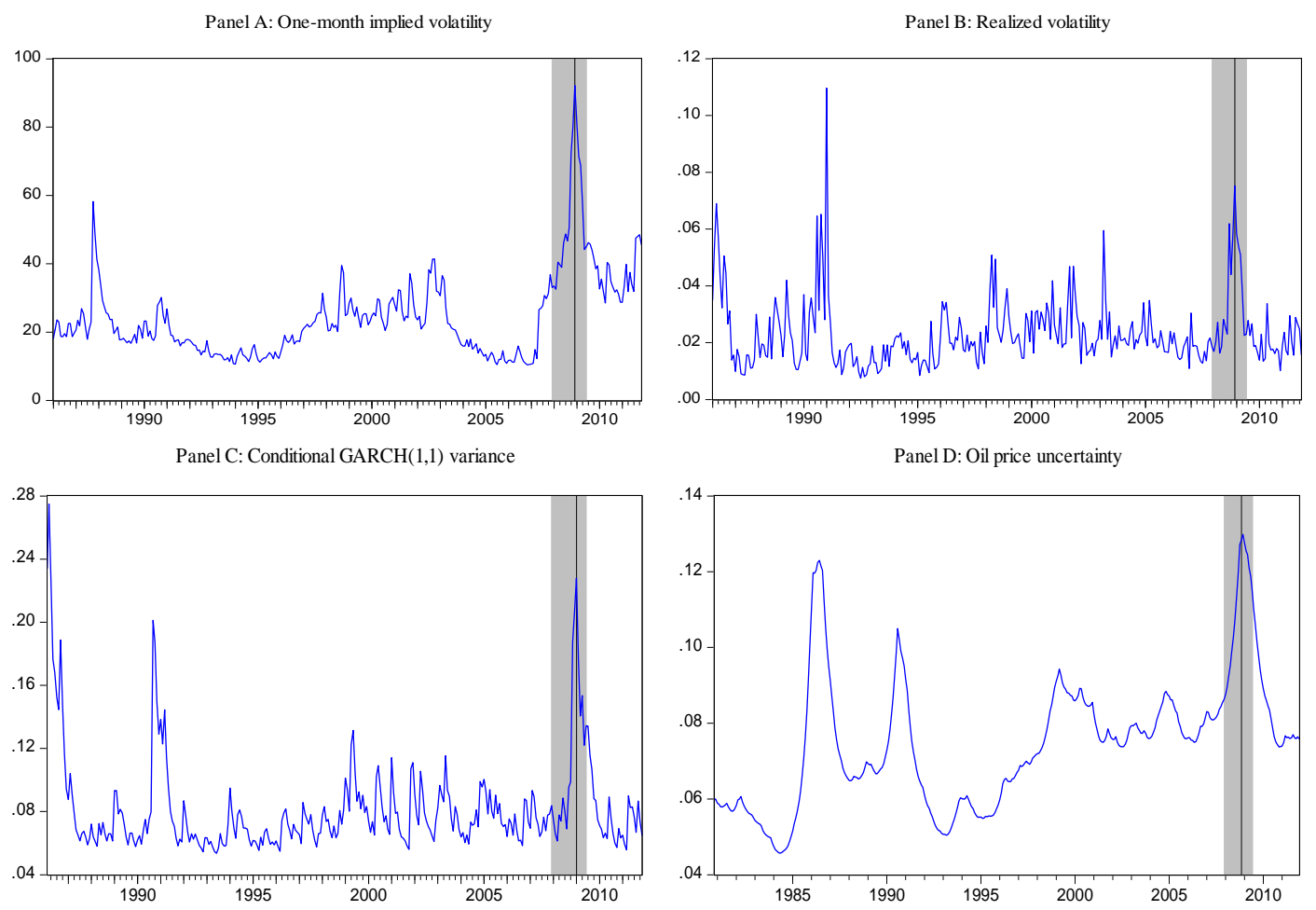

Note : This figure reports alternative measures of oil price uncertainty from 1986M1 to 2011M12. The implied volatility (Panel A) comes from the CBOE VXO crude oil volatility index. The realized volatility (Panel B) is obtained from daily WTI crude oil spot prices. The conditional GARCH volatility (Panel C) is estimated from percent change in the WTI crude oil spot price. The oil price uncertainty (Panel D) is computed from the variance of the forecast errors conditional on macroeconomic uncertainty. The gray band is the NBER recession date for the recent period (2007M12-2009M06), and the vertical black line corresponds to the peak occurence around this period.

price nexus. Considering that commodity price uncertainty is endogenous with respect to macroeconomic uncertainty does not mean that exogenous effects are null or without interest, but rather that they are secondary or indirect. By constructing our proxy of uncertainty based on the global measure of Jurado et al. (2014), we allow both the supply and demand components of the price to exist, but condition the latter to be the primary channel. With regard to this property, our measure of oil price uncertainty is thus theoretically robust, compared to those based on conditional volatility or implied volatility.

Empirically, existing proxies of oil price uncertainty have been so far either based on conditional volatility, implied or realized volatility. However, due to their backward- or forwardlooking nature, it is unclear how these proxies can properly capture oil price uncertainty. To illustrate this issue, Figure 3 reports the one-month implied crude oil volatility from the daily CBOE VXO volatility index (Panel A), the realized volatility estimate constructed 
from daily percent changes in the WTI crude oil spot price ${ }^{82}$ (Panel B), the conditional variance of the percent change of WTI crude oil spot price based on the estimation of a $\operatorname{GARCH}(1,1)$ model (Panel $\mathrm{C}$ ), and our oil price uncertainty measure based on the variance of the forecast errors conditional on macroeconomic uncertainty (Panel D). For almost all series, the most important peak corresponds to the recent, 2007-09 financial turmoil and occurs near the end of 2008. However, major differences between the four proxies can be highlighted regarding their backward- and forward-looking degree. The GARCH-based proxy which peaks on January 2009 is the most backward-looking measure compared to the realized and implied volatility approaches which both peak on December 2008. Our oil price uncertainty proxy conditional on macroeconomic uncertainty is the most forward-looking measure since it peaks on October 2008. Therefore, given the forward-looking nature of investors' expectations, our proxy appears to be the most suitable measure of uncertainty. ${ }^{83}$

\section{Conclusion}

The aim of this paper is to analyze the impact of macroeconomic uncertainty on various raw materials markets. To this end, we consider a large sample of 19 commodities and rely on a robust measure of macroeconomic uncertainty based on a wide range of monthly macroeconomic and financial indicators. To assess whether the effect of macroeconomic uncertainty on commodity price returns depends on the degree of uncertainty, we estimate a nonlinear, structural threshold vector autoregressive model. Our findings show that whereas the safe-haven role of precious metals is confirmed, agricultural and industrial markets are highly sensitive to the variability and the level of macroeconomic uncertainty, respectively. In addition, investigating the links between macroeconomic uncertainty and commodity price uncertainty, we show that the recent 2007-09 recession has generated an unprecedented episode of high uncertainty in the price of numerous raw materials, especially those that are linked to global economic activity. Finally, we find evidence that uncertainty episodes are not necessarily accompanied by high volatility in commodity prices, highlighting the relevance of our uncertainty measure in linking uncertainty to predictability rather than to volatility.

\footnotetext{
${ }^{82}$ See Bachmeier, Li and Liu (2008).

${ }^{83}$ Another way to compare alternative measures of oil price uncertainty is to test which approach leads to the best predictor of volatility. Alquist et al. (2010) showed that the oil futures price is of limited use in forecasting the oil price, questioning the interest of using the implied volatility to measure uncertainty.
} 


\section{References}

Alquist, Ron, and Lutz Kilian (2010). "What do We Learn form the Price of Crude Oil Futures?" Journal of Applied Econometrics 25, 539-573.

Alquist, Ron, Lutz Kilian, and Robert J. Vigfusson (2013). "Forecasting the Price of Oil." In Elliott G, Timmermann A (eds.), Handbook of Economic Forecasting 2, 427-507.

Arellano, Cristina, Yan Bai, and Patrick Kehoe (2011). "Financial Markets and Fluctuations in Uncertainty." Federal Reserve Bank of Minneapolis Research Department Staff Report.

Bachmann, Rüdiger, and Christian Bayer (2011). "Uncertainty Business Cycles - Really?" NBER Working Paper 16862, National Bureau of Economic Research, March.

Bachmann, Rüdiger, Steffen Elstner, and Eric R. Sims (2013). "Uncertainty and Economic Activity: Evidence from Business Survey Data." American Economic Journal: Macroeconomics 5, 217249.

Bachmeier, Lance, Qi Li, and Dandan Liu (2008). "Should Oil Prices Receive So Much Attention? An Evaluation of the Predictive Power of Oil Prices for the U.S. Economy". Economic Inquiry $46,528-539$.

Baker, Scott R., Nicholas Bloom, and Steven J. Davis (2011). "Measuring Economic Policy Uncertainty." Unpublished paper, Stanford University.

Balke, Nathan (2000). "Credit and economic activity: Credit regimes and nonlinear propagation of shocks." The Review of Economics and Statistics 82, 344-349.

Basu, Suranto, and Brent Bundick (2011). "Uncertainty Shocks in a Model of Effective Demand." Unpublished paper, Boston College.

Barsky, Robert B., and Lutz Kilian (2002). "Do We Really Know that Oil Caused the Great Stagflation? A Monetary Alternative." In B. Bernanke and K. Rogoff (eds.), NBER Macroeconomics Annual 2001, May 2002, 137-183.

Barsky, Robert B., and Lutz Kilian (2004). "Oil and the Macroeconomy since the 1970s." Journal of Economic Perspectives 18(4), 115-134.

Baumeister, Christiane, and Lutz Kilian (2014). "Do Oil Price Increases Cause Higher Food Prices?" Economic Policy 80, 691-747.

Baumeister, Christiane, and Gert Peersman (2013). "The Role of Time-Varying Price Elasticities in Accounting for Volatility Changes in the Crude Oil Market." Journal of Applied Econometrics 28(7), 1087-1109. 
Bernanke, Ben S. (1983). "Irreversibility, uncertainty, and cyclical investment." The Quarterly Journal of Economics 98, 85-106.

Blanchard, Olivier J., and Jordi Gali (2007) "The Macroeconomic Effects of Oil Shocks: Why are the 2000s so different from the 1970s?" NBER Working Paper 13368, National Bureau of Economic Research.

Bloom, Nicholas (2009). "The impact of uncertainty shocks." Econometrica 77, 623-685.

Bloom, Nicholas (2014). "Fluctuations in Uncertainty." Journal of Economic Perspectives 28, 153176.

Bloom, Nicholas, Stephen Bond, and John Van Reenen (2007). "Uncertainty and investment dynamics." Review of Economic Studies 74, 391-415.

Bloom, Nicholas, Max Floetotto, and Nir Jaimovich (2010) "Really Uncertain Business Cycles." Mimeo, Stanford University.

Bloom, Nicholas, Max Floetotto, Nir Jaimovich, Itay Saporta-Eksten, and Stephen J. Terry (2012). "Really Uncertain Business Cycles." NBER Working Paper 18245, National Bureau of Economic Research, July.

Bredin Don, Thomas Conlon, and Valerio Potì (2014). "Does gold glitter in the long-run? Gold as hedge and safe haven across time and investment horizon." Mimeo.

Bredin Don, John Elder, and Stilianos Fountas (2011). "Oil volatility and the option value of waiting: An analysis of the G-7." The Journal of Futures Markets 31, 679-702.

Brennan, Michael J. (1990). "Presidential Address: Latent Assets." Journal of Finance 45, 709-730.

Brennan, Michael J., and Eduardo S. Schwartz (1985) "Evaluating natural resource investments." The Journal of Business 58, 135-157.

Chan, Joshua C. C., and Cody Y. L. Hsiao (2013). "Estimation of Stochastic Volatility Models with Heavy Tails and Serial Dependence." CAMA Working Paper 2013-74, Centre for Applied Macroeconomic Analysis, Crawford School of Public Policy, The Australian National University.

Chan, Joshua C. C., and Ivan Jeliazkov (2009). "Efficient Simulation and Integrated Likelihood Estimation in State Space Models." International Journal of Mathematical Modelling and Numerical Optimisation 1, 101-120.

Christie-David, Rohan, Mukesh Chaudry, and Timothy W. Koch. (2000). "Do macroeconomics news releases affect gold and silver prices?" Journal of Economics and Business 52, 405-421.

Creti, Anna, Marc Joëts, and Valérie Mignon (2013). "On the links between stock and commodity markets' volatility." Energy Economics 37, 16-28. 
Davis, Steven J., and John Haltiwanger (2001). "Sectoral Job Creation and Destruction Responses to Oil Changes." Journal of Monetary Economics 48, 456-512.

Dvir, Eyal and Kenneth Rogoff (2010). "Three Epochs of Oil." NBER Working Paper No. 14927, National Bureau of Economic Research.

Edelstein, Paul, and Lutz Kilian (2007). "The Response of Business Fixed Investment to Changes in Energy Prices: A Test of Some Hypotheses about the Transmission of Energy Price Shocks." The B.E. Journal of Macroeconomics 7, 1-41.

Edelstein, Paul, and Lutz Kilian (2009). "How Sensitive are Consumer Expenditures to Retail Energy Prices?". Journal of Monetary Economics 56(6), 766-779.

Elder, John, and Apostolos Serletis (2009). "Oil price uncertainty in Canada." Energy Economics 31, 852-856.

Elder, John, and Apostolos Serletis (2010). "Oil price uncertainty." Journal of Money, Credit and Banking 42, 1137-1159.

Fattouh, Bassam, Lutz Kilian, and Lavan Mahadeva (2013). "The Role of Speculation in Oil Markets: What Have We Learned So Far?" The Energy Journal 34(3), 7-33.

Favero, Carlo A., M. Hashem Pesaran, and Sunil Sharma (1994). "A duration model of irreversible oil investment: Theory and empirical evidence." Journal of Applied Econometrics 9, 95-112.

Ferderer, Peter J. (1996). "Oil Price Volatility and the Macroeconomy: A Solution to the Asymmetry Puzzle." Journal of Macroeconomics 18, 1-16.

Fernández-Villaverde, Jesús, Juan F. Rubio-Ramírez, Pablo Guerrón-Quintana, and Martin Uribe (2011). "Risk Matters: The Real Effects of Volatility Shocks." American Economic Review 6, 2530-2561.

Gabaix, Xavier (2011). "The Granular Origins of Aggregate Fluctuations." Econometrica 79(3), 733-772.

Gibson, Rajna, and Eduardo S. Schwartz (1990). "Stochastic Convenience Yield and the Pricing of Oil Contingent Claims." Journal of Finance 45, 959-976.

Gilchrist, Simon, Jae W. Sim, and Egon Zakrajšek (2010). "Uncertainty, Financial Frictions, and Investment Dynamics." Unpublished Manuscript, Boston University.

Greasley, David, and Jakob B. Madsen (2006). "Investment and Uncertainty: Precipitating the Great Depression in the United States." Economica 73(291), 393-412.

Green, Edward J., and Robert H. Porter (1984). "Noncooperative Collusion under Imperfect Price Information." Econometrica 52, 87-100. 
Hamilton, James D. (1988). "A Neoclassical Model of Unemployment and the Business Cycle." Journal of Political Economy 96, 593-617.

Hamilton, James D. (1996). "This is What Happened to the Oil-Price Macroeconomy Relationship." Journal of Monetary Economics 38, 215-220.

Hamilton, James D. (2003). "What Is an Oil Shock?" Journal of Econometrics 113, 363-398.

Hamilton, James D. (2009). "Causes and Consequences of the Oil Shock of 2007-08." Brookings Papers on Economic Activity 40, 215-283

Hansen, Bruce E. (1996). "Inference when a nuisance parameter is not identified under the null hypothesis." Econometrica 64, 413-430.

Hansen, Bruce E. (2011). "Threshold Autoregression in Economics." Statistics and its Interface 4, 123-127.

Hassler, John (2001). "Uncertainty and the Timing of Automobile Purchases." Scandinavian Journal of Economics 103(2), 351-366.

Henry, Claude (1974). "Investment decisions under uncertainty: The 'irreversibility effect'." The American Economic Review 64, 1006-1012.

Herrera, Ana Maria, Latika G. Lagalo, and Tatsuma Wada (2011). "Oil Price Shocks and Industrial Production: Is the Relathionship Linear?" Macroeconomic Dynamics 15(3), 472-497.

Jo, Soojin (2014). "The Effect of Oil Price Uncertainty on Global Real Economic Activity." Journal of Money, Credit, and Banking 46(6), 1113-1135.

Johnson Matthey Plc. (2008). Platinum 2008. Royston, UK: Johnson Matthey.

Jurado, Kyle, Sydney Ludvigson, and Serena Ng (2014). "Measuring Uncertainty." American Economic Review (forthcoming).

Kilian, Lutz (2008a). "The Economic Effects of Energy Price Shocks." Journal of Economic Literature 46(4), 871-909.

Kilian, Lutz (2008b). "Exogenous Oil Supply Shocks: How Big Are They and How Much Do They Matter for the U.S. Economy?" Review of Economics and Statistics 90, 216-240.

Kilian, Lutz (2009). "Not all oil price shocks are alike: Disentangling Demand and Supply Shocks in the Crude Oil Market." American Economic Review 99, 1053-1069.

Kilian, Lutz (2010). "Explaining Fluctuations in Gasoline Prices: A Joint Model of the Global Crude Oil Market and the U.S. Retail Gasoline Market." The Energy Journal 31(2), 87-104. 
Kilian, Lutz (2014). "Oil Price Shocks: Causes and Consequences." Annual Review of Resource Economics 6, 133-154.

Kilian, Lutz, and Bruce Hicks (2013). "Did Unexpectedly Strong Economic Growth Cause the Oil Price Shock of 2003-2008?" Journal of Forecasting 32(5), 385-394.

Kilian, Lutz, and Thomas K. Lee (2014). "Quantifying the Speculative Component in the Real Price of Oil: the Role of Global Oil Inventories." Journal of International Money and Finance 42, 71-87.

Kilian, Lutz, and Logan T. Lewis (2011). "Does the Fed Respond to Oil price Shocks?". Economic Journal 121, 1047-1072.

Kilian, Lutz, and Daniel P. Murphy (2012). "Why Agnostic Sign Restrictions Are Not Enough: Understanding the Dynamics of Oil Market VAR Models." Journal of European Economic Association 10(5), 1166-1188.

Kilian, Lutz, Daniel P. Murphy (2014). "The role of inventories and speculative trading in the global market for crude oil.” Journal of Applied Econometrics 29, 454-478.

Kilian, Lutz, and Cheolbeom Park (2009). "The Impact of Oil Price Shocks on the U.S. Stock Market." International Economic Review 50(4), 1267-1287.

Kilian, Lutz, and Clara Vega (2011). "Do Energy Prices Respond to U.S. Macroeconomic News? A Test of the Hypothesis of Predetermined Energy Prices " Review of Economics and Statistics 93(2), 660-671.

Kilian, Lutz, and Robert J. Vigfusson (2011a). "Nonlinearities in the Oil Price-Output Relationship". Macroeconomic Dynamics 15(3), 337-363.

Kilian, Lutz, and Robert J. Vigfusson (2011b) "Are the Responses of the U.S. Economy Asymmetric in Energy Price Increases and Decreases?" Quantitative Economics 2, 419-453.

Knittel, Christopher R. and Robert S. Pindyck (2013). "The Simple Economics of Commodity Price Speculation." NBER Working Paper 18951, National Bureau of Economic Research, April.

Knotek, Edward S., and Shujaat Khan (2011). "How Do Households Respond to Uncertainty Shocks?" Federal Reserve Bank of Kansas City Economic Review 96, 5-34.

Leahy, John V., and Toni M. Whited (1996). "The Effect of Uncertainty on Investment: Some Stylized Facts." Journal of Money, Credit, and Banking 28(1), 64-83.

Leduc, Sylvain, and Zheng Liu (2012). "Uncertainty Shocks are Aggregate Demand Shocks." Federal Reserve Bank of San Francisco, Working Paper 2012-10. 
Leduc, Sylvain, and Keith Sill (2004). "A quantitative analysis of oil-price shocks, systematic monetary policy, and economic downturns." Journal of Monetary Economics 51(4), 781-808.

Lee, Kiseok, and Shawn Ni (2002). "On the dynamic effects of oil price shocks: a study using industry level data." Journal of Monetary Economics 49, 823-852.

Lee, Kiseok, Shawn Ni, and Ronald A. Ratti (1995). "Oil shocks and the macroeconomy: The role of price variability." The Energy Journal 16, 39-56.

Litzenberger, Robert H., and Nir Rabinowitz (1995). "Backwardation in oil futures markets: Theory and empirical evidence." The Journal of Finance 50, 1517-1545.

Mabro, Robert (1998). "The Oil Price Crisis of 1998." Oxford Institute for Energy Studies.

Majd, Saman, and Robert S. Pindyck (1987). "The learning curve and optimal production under uncertainty." MIT Working Paper 1948-87, Cambridge, MA: MIT Press.

Nakamura, Emi, Dmitriy Sergeyev, and Jón Steinsson (2012). "Growth-Rate and Uncertainty Shocks in Consumption: Cross-Country Evidence." Working Paper, Columbia University.

Orlik, Anna, and Laura Veldkamp (2013). "Understanding Uncertainty Shocks." Unpublished manuscript, New York University Stern School of Business.

Pindyck, Robert S. (1980). "Uncertainty and exhaustible resource markets." The Journal of Political Economy 88, 1203-1225.

Pindyck, Robert S. (1991). "Irreversibility, uncertainty and investment." Journal of Economic Literature 29, 1110-1148.

Poon, Ser-Huang., and Clive W.J. Granger (2003). "Forecasting volatility in financial markets: a review." Journal of Economic Literature 41, 478-539.

Roache, Shaun K., and Marco Rossi (2009). "The effects of economic news on commodity prices: Is gold just another commodity?" IMF Working Paper 140, International Monetary Fund, July.

Romer, Christina D. (1990). "The Great Crash and the Onset of the Great Depression." Quarterly Journal of Economics 105(3), 597-624.

Rotemberg, Julio J., and Garth Saloner (1986). "A Supergame-Theoretic Model of Price Wars during Booms." American Economic Review 76(3), 390-407.

Rotemberg, Julio J., and Michael Woodford (1996). "Imperfect Competition and the Effects of Energy Price Increases on Economic Activity." Journal of Money, Credit, and Banking 28, 549-577.

Schaal, Edouard (2012). "Uncertainty, Productivity, and Unemployment in the Great Recession." Unpublished paper, Princeton University, Princeton, NJ. 
Tang, Ke, and Wei Xiong (2011). "Index Investment and Financialization of Commodities." Working Paper, Princeton University.

Tong, Howell (2010). "Threshold Models in Time Series Analysis-30 Years On." Research Report 471, University of Hong Kong.

Van Robays, Ine (2013). "Macroeconomic uncertainty and the impacts of oil shocks." ECB Working Paper 1479, European Central Bank.

Venditti, Fabrizio (2013). "From Oil to Consumer Energy Prices: How much Asymmetry along the Way?" Energy Economics 40, 468-473.

Windschitl, Paul A., and Gary L. Wells (1996). "Measuring Psychological Uncertainty: Verbal Versus Numeric Method." Journal of Experimental Psychology: Applied 2, 343-364. 


\section{Appendix A. Data sources and threshold test results}

Table 1 - Commodity dataset

\begin{tabular}{|c|c|c|c|c|}
\hline & Period & Description & Transformation & Source \\
\hline \multicolumn{5}{|c|}{ Energy markets } \\
\hline Oil & 1978M10-2011M12 & WTI crude oil spot price & $\Delta \ln$ & NYMEX \\
\hline Gas & 1978M10-2011M12 & Henry Hub & $\Delta \ln$ & NYMEX \\
\hline \multicolumn{5}{|c|}{ Precious metals markets } \\
\hline Gold & 1976M02-2011M12 & Gold spot price & $\Delta \ln$ & COMEX \\
\hline Platinum & 1976M02-2011M12 & Platinum spot price & $\Delta \ln$ & LME \\
\hline Silver & 1976M02-2011M12 & Silver spot price & $\Delta \ln$ & COMEX \\
\hline \multicolumn{5}{|c|}{ Agricultural markets } \\
\hline Cocoa & 1980M02-2011M12 & ICO price & $\Delta \ln$ & IMF \\
\hline Coffee & 1980M02-2011M12 & Composite indicator price & $\Delta \ln$ & UNCTAD \\
\hline Corn & 1980M02-2011M12 & Corn Chicago price & $\Delta \ln$ & COMEX \\
\hline Cotton & 1980M02-2011M12 & Cotton price, CIF Liverpool & $\Delta \ln$ & IMF \\
\hline Lumber & 1980M02-2011M12 & Hard Sawnwood & $\Delta \ln$ & IMF \\
\hline Soybeans & 1980M02-2011M12 & Soybeans Chicago price & $\Delta \ln$ & COMEX \\
\hline Sugar & 1980M02-2011M12 & World Raw & $\Delta \ln$ & COMEX \\
\hline Wheat & 1980M02-2011M12 & Wheat Minneapolis price & $\Delta \ln$ & MGEX \\
\hline \multicolumn{5}{|c|}{ Industrial markets } \\
\hline Aluminium & 1980M02-2011M12 & Alu spot price & $\Delta \ln$ & LME \\
\hline Copper & 1980M02-2011M12 & CIF Europe & $\Delta \ln$ & IMF/LME \\
\hline Lead & 1980M02-2011M12 & CIF Europe & $\Delta \ln$ & IMF/LME \\
\hline Nickel & 1980M02-2011M12 & CIF Europe & $\Delta \ln$ & IMF/LME \\
\hline Tin & 1980M02-2011M12 & CIF Europe & $\Delta \ln$ & IMF/LME \\
\hline Zinc & 1980M02-2011M12 & CIF UK & $\Delta \ln$ & IMF/LME \\
\hline
\end{tabular}

Note: $\Delta$ In denotes the first-logarithmic difference transformation. 
Table 2 - Tests for the threshold effect in energy markets at 1, 3 and 12 months

\begin{tabular}{l|c|ccc|c}
\hline \hline Horizon $h$ & Threshold & \multicolumn{3}{|c|}{ Wald Statistics } & \% high uncertainty \\
& value & Sup-Wald & Avg-Wald & Exp-Wald & \\
\hline & & & & & \\
$h=1$ & 0.7596 & $101.84\left(0.000^{*}\right)$ & $52.15\left(0.030^{* *}\right)$ & $45.51\left(0.000^{*}\right)$ & $18.25 \%$ \\
$h=3$ & 0.9138 & $111.38\left(0.000^{*}\right)$ & $53.90\left(0.010^{* *}\right)$ & $51.22\left(0.000^{*}\right)$ & $18.00 \%$ \\
$h=12$ & 0.9890 & $90.42\left(0.000^{*}\right)$ & $48.50\left(0.000^{*}\right)$ & $40.51\left(0.000^{*}\right)$ & $16.25 \%$ \\
\hline \hline
\end{tabular}

Notes: sup-Wald: maximum Wald statistic over all possible threshold values, avg-Wald: average

Wald statistic over all possible values, exp-Wald: function of the sum of exponential Wald statistics. Corresponding $p$-values are given in parentheses. ${ }^{*}, * *$ denote the rejection of the null hypothesis at $1 \%$ and $5 \%$ significance levels, respectively.

Table 3 - Tests for the threshold effect in precious metals markets at 1,3 and 12 months

\begin{tabular}{l|c|ccc|c}
\hline \hline Horizon $h$ & Threshold & \multicolumn{3}{|c|}{ Wald Statistics } & \% high uncertainty \\
& value & Sup-Wald & Avg-Wald & Exp-Wald & \\
\hline & & & & & \\
$h=1$ & 0.7509 & $184.15\left(0.000^{*}\right)$ & $92.34\left(0.002^{*}\right)$ & $87.41\left(0.000^{*}\right)$ & $17.59 \%$ \\
$h=3$ & 0.9091 & $194.31\left(0.000^{*}\right)$ & $99.28\left(0.000^{*}\right)$ & $91.98\left(0.000^{*}\right)$ & $16.90 \%$ \\
$h=12$ & 0.9798 & $194.45\left(0.000^{*}\right)$ & $103.58\left(0.000^{*}\right)$ & $91.94\left(0.000^{*}\right)$ & $17.83 \%$ \\
\hline \hline
\end{tabular}

Notes: sup-Wald: maximum Wald statistic over all possible threshold values, avg-Wald: average

Wald statistic over all possible values, exp-Wald: function of the sum of exponential Wald statistics. Corresponding $p$-values are given in parentheses. ${ }^{*}$ denotes the rejection of the null hypothesis at the $1 \%$ significance level.

Table 4 - Tests for the threshold effect in industrial markets at 1, 3 and 12 months

\begin{tabular}{l|c|ccc|c}
\hline \hline Horizon $h$ & Threshold & \multicolumn{3}{|c|}{ Wald Statistics } & \% high uncertainty \\
& value & Sup-Wald & Avg-Wald & Exp-Wald & \\
\hline & & & & & \\
$h=1$ & 0.7155 & $431.73\left(0.000^{*}\right)$ & $326.01\left(0.001^{*}\right)$ & $211.61\left(0.000^{*}\right)$ & $23.70 \%$ \\
$h=3$ & 0.8542 & $442.03\left(0.000^{*}\right)$ & $318.74\left(0.000^{*}\right)$ & $216.16\left(0.000^{*}\right)$ & $32.29 \%$ \\
$h=12$ & 0.9481 & $432.07\left(0.000^{*}\right)$ & $325.11\left(0.000^{*}\right)$ & $210.79\left(0.000^{*}\right)$ & $35.16 \%$ \\
\hline \hline
\end{tabular}

Notes: sup-Wald: maximum Wald statistic over all possible threshold values, avg-Wald: average

Wald statistic over all possible values, exp-Wald: function of the sum of exponential Wald statistics. Corresponding $p$-values are given in parentheses. ${ }^{*}$ denotes the rejection of the null hypothesis at the $1 \%$ significance level. 
Table 5 - Tests for the threshold effect in agricultural markets at 1, 3 and 12 months

\begin{tabular}{l|c|ccc|c}
\hline \hline Horizon $h$ & Threshold & \multicolumn{3}{|c|}{ Wald Statistics } & \% high uncertainty \\
& value & Sup-Wald & Avg-Wald & Exp-Wald & \\
\hline & & & & & \\
$h=1$ & 0.6827 & $467.27\left(0.000^{*}\right)$ & $432.00\left(0.000^{*}\right)$ & $229.12\left(0.000^{*}\right)$ & $42.45 \%$ \\
$h=3$ & 0.8780 & $507.56\left(0.000^{*}\right)$ & $453.68\left(0.000^{*}\right)$ & $248.53\left(0.000^{*}\right)$ & $22.92 \%$ \\
$h=12$ & 0.9668 & $539.70\left(0.000^{*}\right)$ & $462.15\left(0.000^{*}\right)$ & $264.91\left(0.000^{*}\right)$ & $23.44 \%$ \\
\hline \hline
\end{tabular}

Notes: sup-Wald: maximum Wald statistic over all possible threshold values, avg-Wald: average

Wald statistic over all possible values, exp-Wald: function of the sum of exponential Wald statistics. Corresponding $p$-values are given in parentheses. ${ }^{*}$ denotes the rejection of the null hypothesis at the $1 \%$ significance level. 


\section{Appendix B. Evolution of macroeconomic uncertainty measure at 1 month}

Figure 1B. Uncertainty and threshold values for commodity markets at 1 month
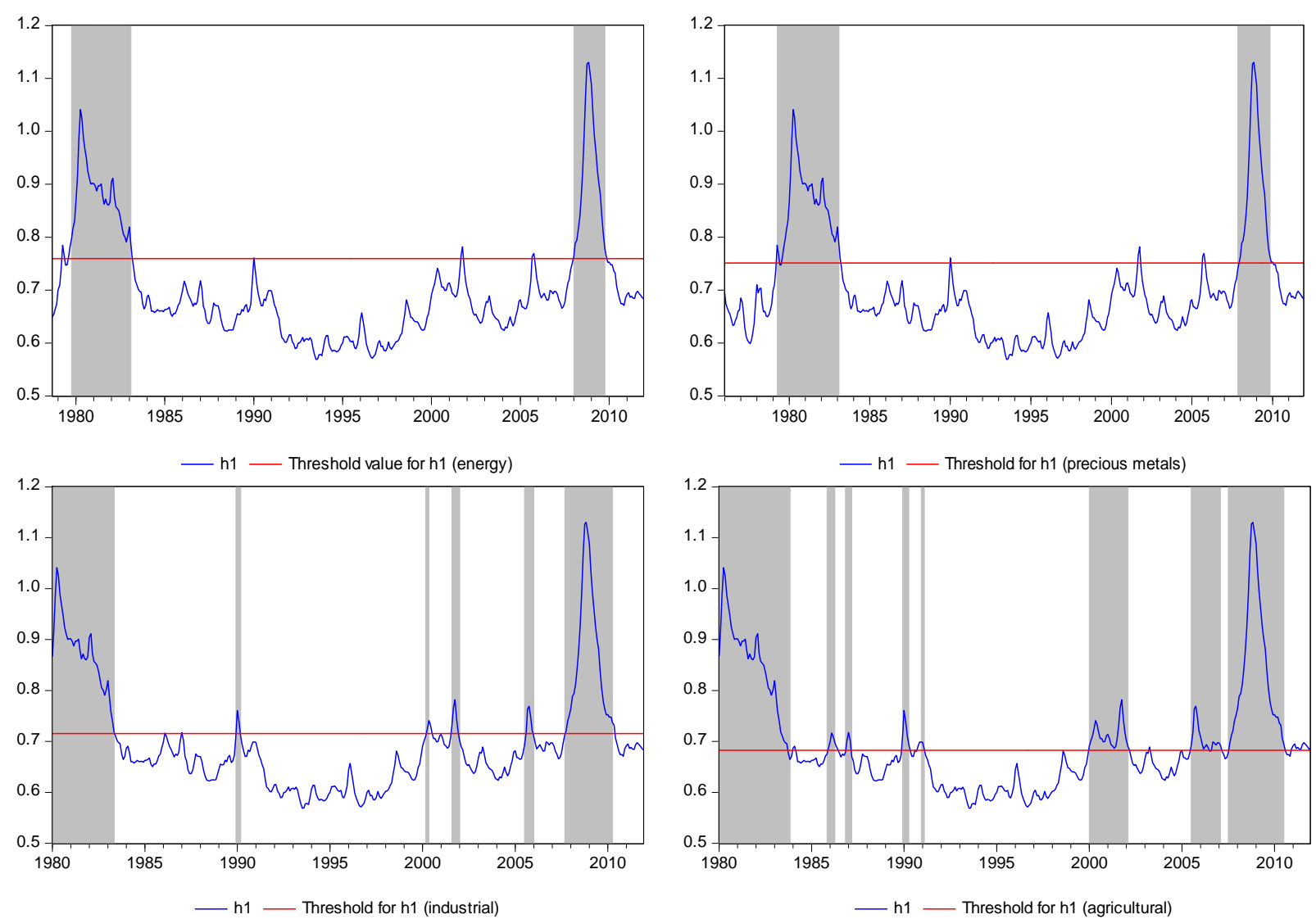

Note: These figures depict macroeconomic uncertainty proxy at 1 month ( $h 1$, blue line) and the corresponding estimated threshold value (horizontal red bar) for each group of commodities (energy, precious metals, industry, and agriculture). Vertical gray bands indicate the percentage of high uncertainty (corresponding to the case where uncertainty proxy is above the estimated threshold). 


\section{Appendix C. Impact of macroeconomic uncertainty at 1 month}

Figure 1C. Impulse-response functions for energy markets in high- and low-uncertainty regimes

Response of oil price to h1 shock

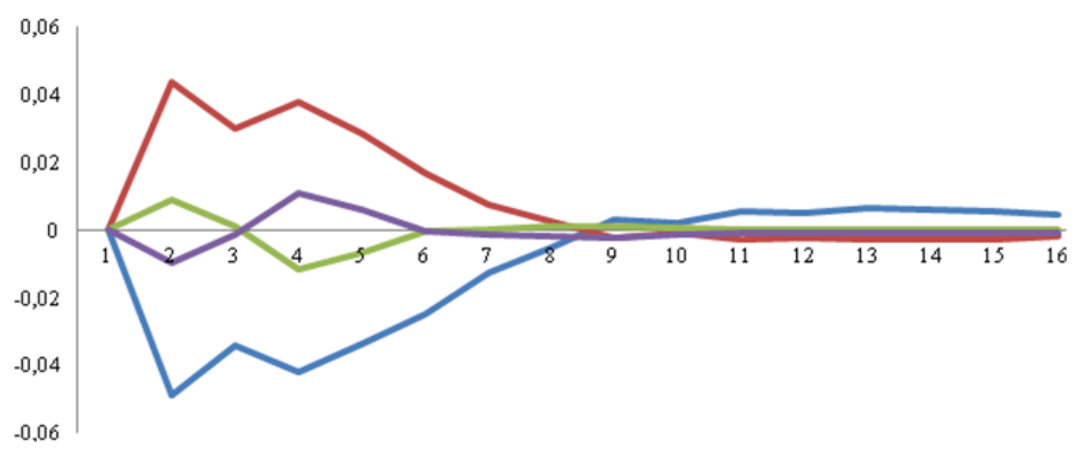

Response of gas price to hl shock

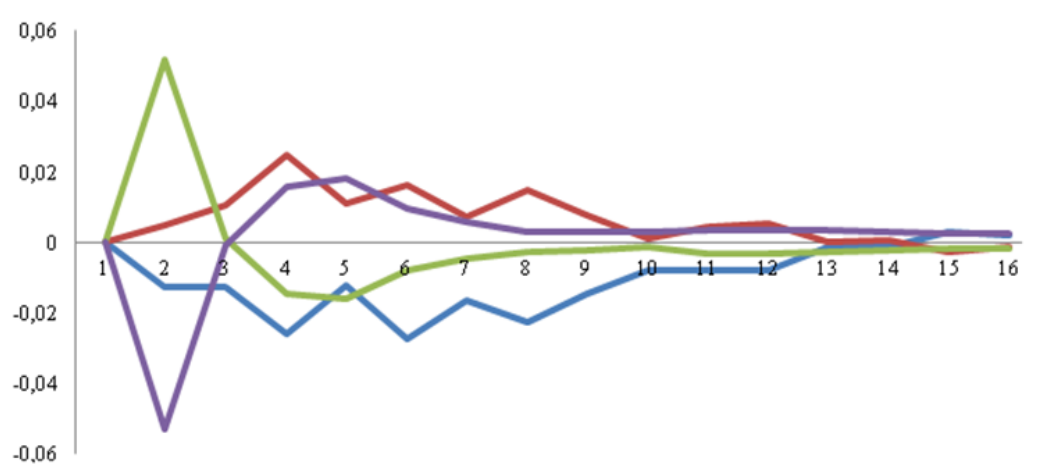

Note: These figures report the response to positive and negative two-standard-deviation shocks. Blue line corresponds to "positive high uncertainty", red line to "negative high uncertainty", green line to "positive low uncertainty" and purple line to "negative low uncertainty". 
Figure 2C. Impulse-response functions for precious metals markets in high- and low-uncertainty regimes

Response of gold price to h1 shock

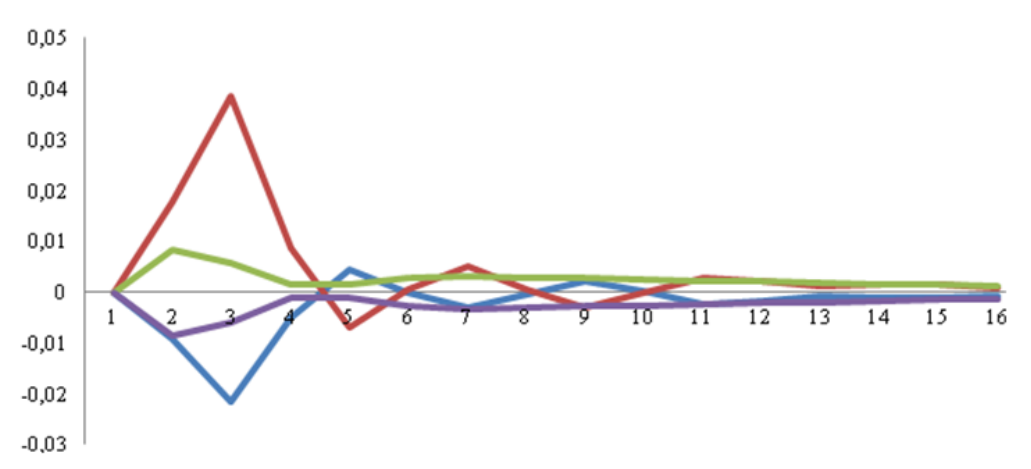

Response of platinum price to h1 shock

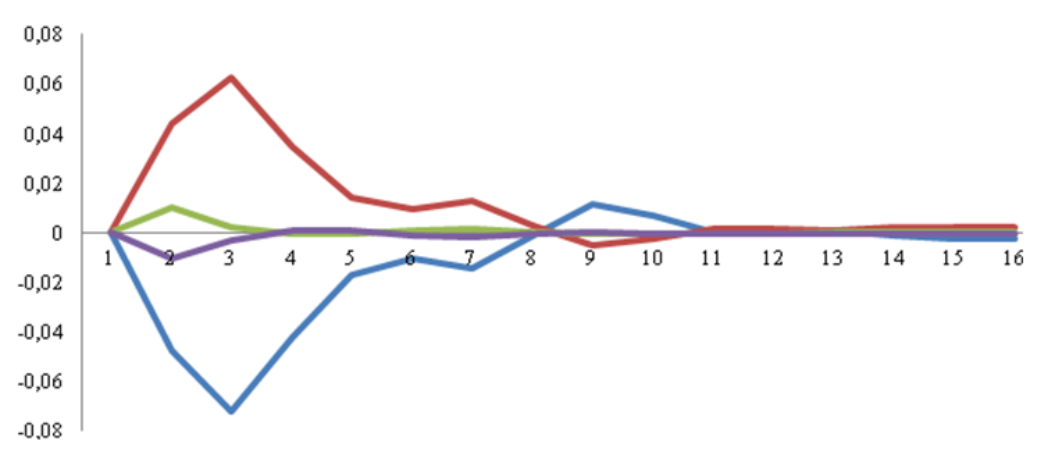

Response of silver price to $\mathrm{h} 1$ shock

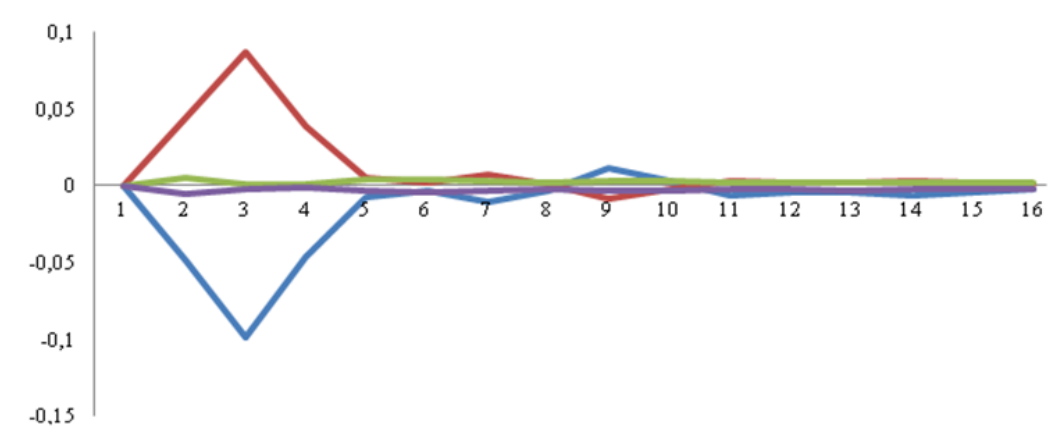

Note: These figures report the response to positive and negative two-standard-deviation shocks. Blue line corresponds to "positive high uncertainty", red line to "negative high uncertainty", green line to "positive low uncertainty" and purple line to "negative low uncertainty". 
Figure 3C. Impulse-response functions for industrial markets in high- and low-uncertainty regimes

Response of aluminium price to h1 shock

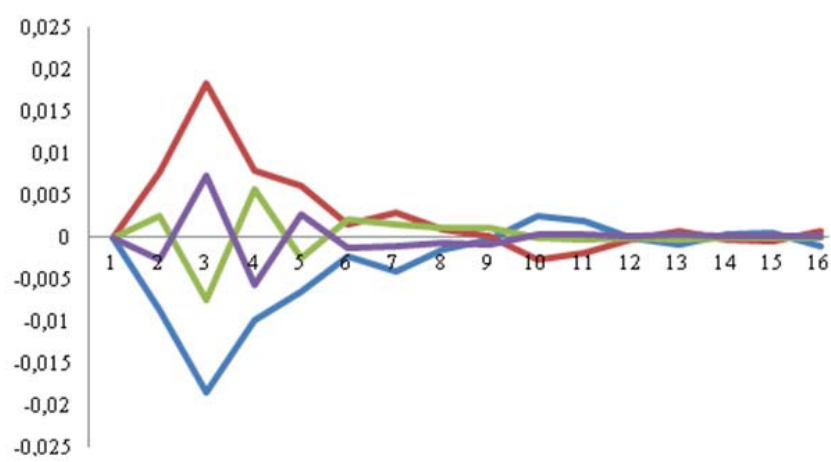

Response of lead price to $\mathrm{h} 1$ shock

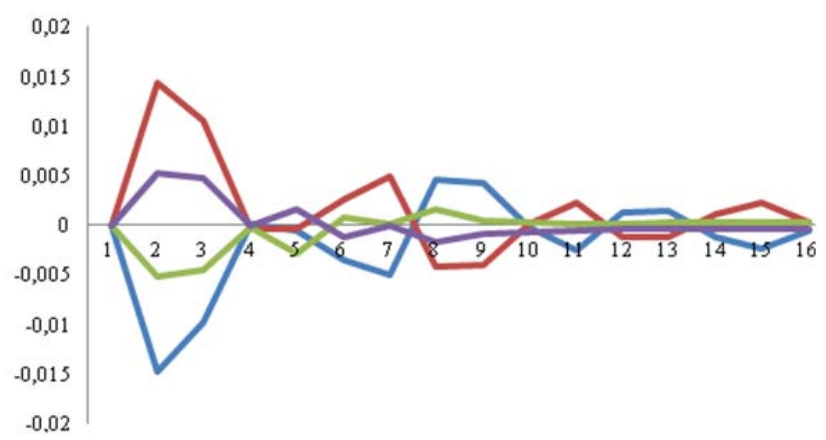

Response of tin price to hl shock

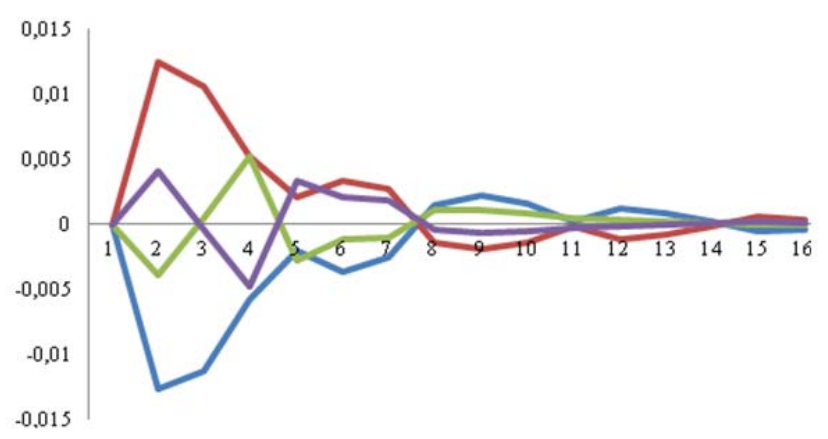

Response of copper price to hl shock

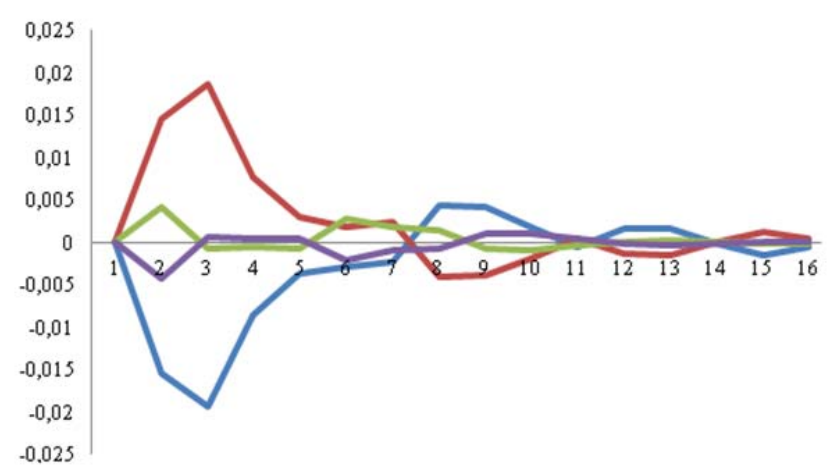

Response of nickel price to h1 shock

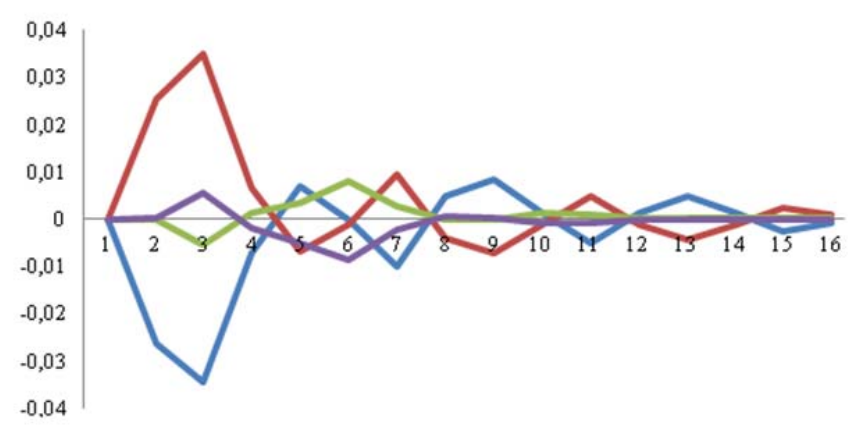

Response of zinc price to h1 shock

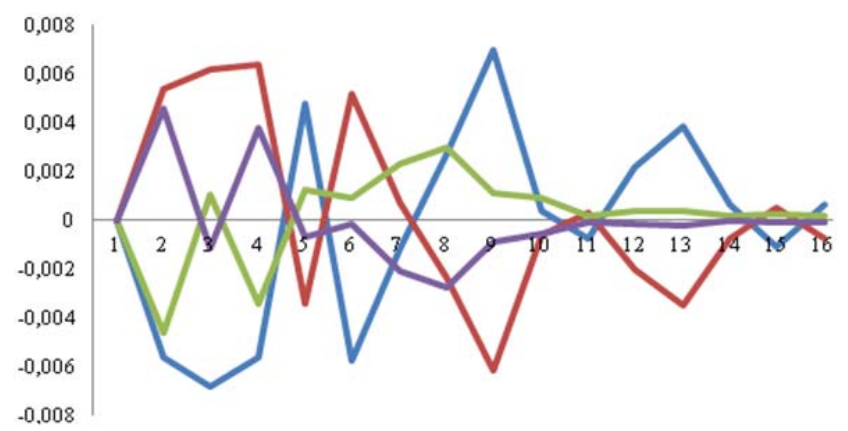

Note: These figures report the response to positive and negative two-standard-deviation shocks. Blue line corresponds to "positive high uncertainty", red line to "negative high uncertainty", green line to "positive low uncertainty" and purple line to "negative low uncertainty". 
Figure 4C. Impulse-response functions for agricultural markets in high- and low-uncertainty regimes

Response of cocoa price to hl shock

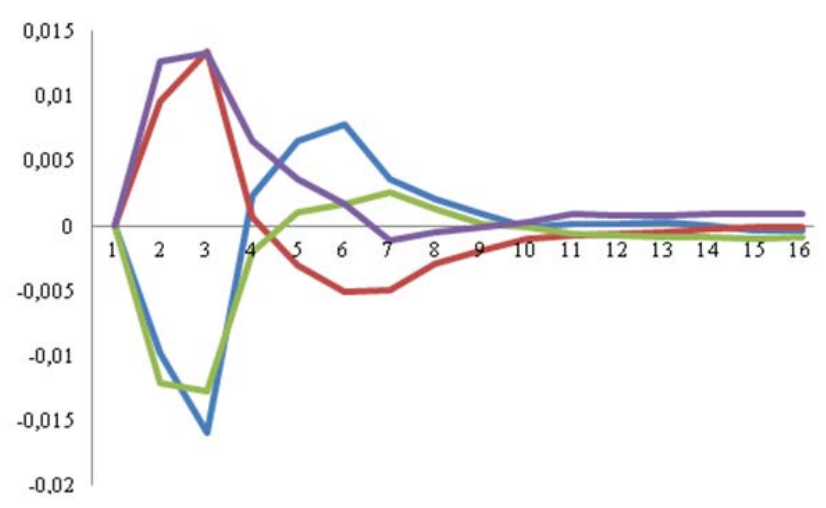

Response of com price to h1 shock

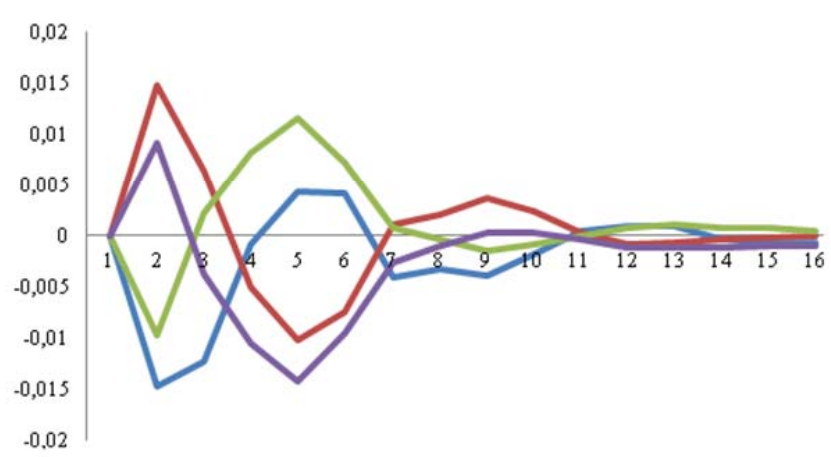

Response of lumber price to h1 shock

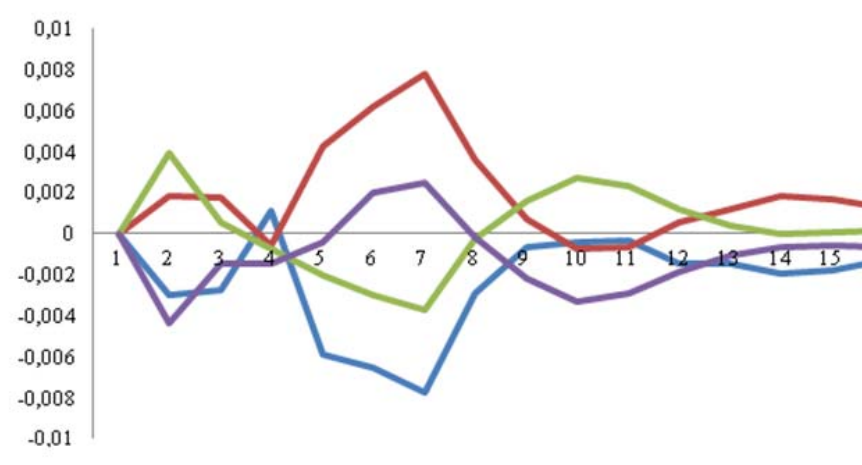

Response of coffee price to h1 shock

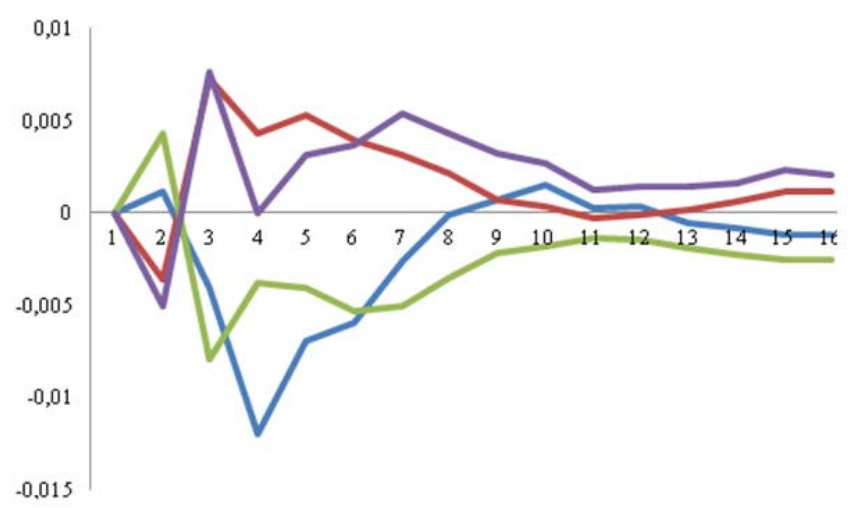

Response of cotton price to $\mathrm{h} 1$ shock

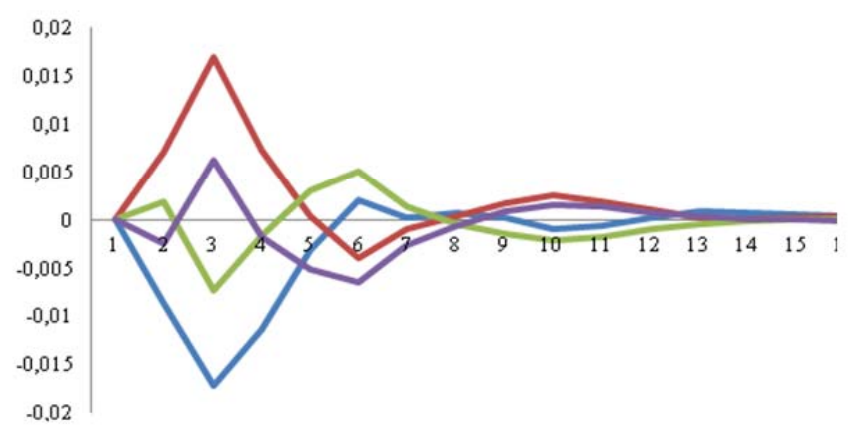

Response of soybeans price to hl shock

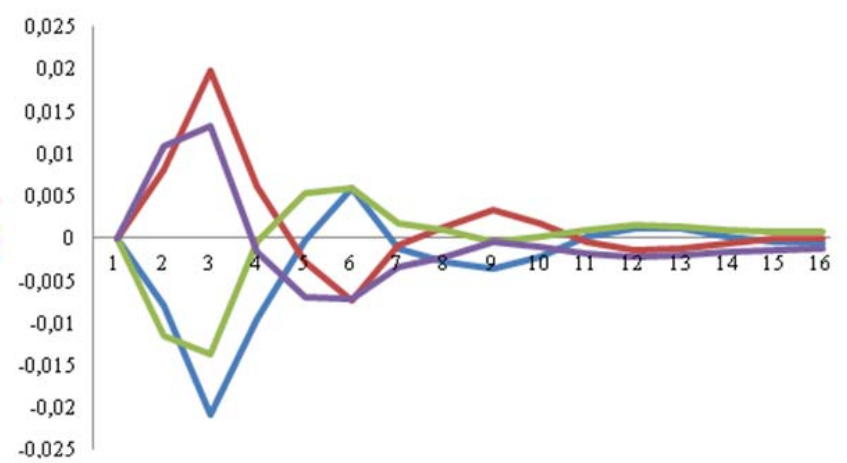

Note: These figures report the response to positive and negative two-standard-deviation shocks. Blue line corresponds to "positive high uncertainty", red line to "negative high uncertainty", green line to "positive low uncertainty" and purple line to "negative low uncertainty". 
Figure 4C (cont.)

Response of sugar price to hl shock

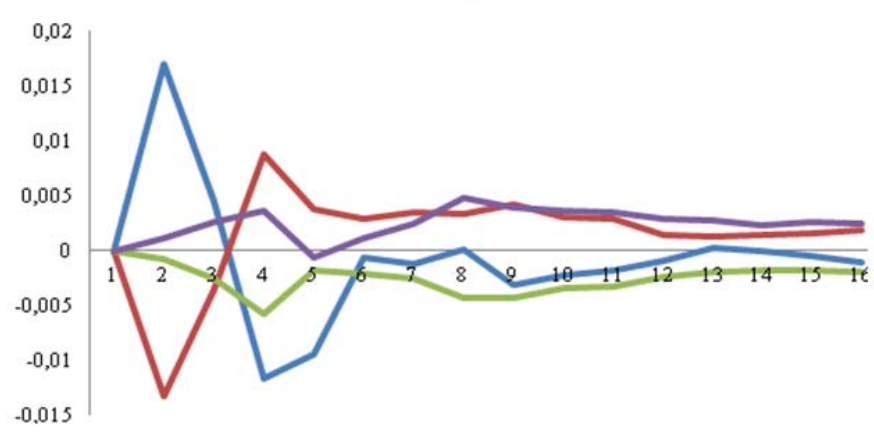

Response of wheat price to hl shock

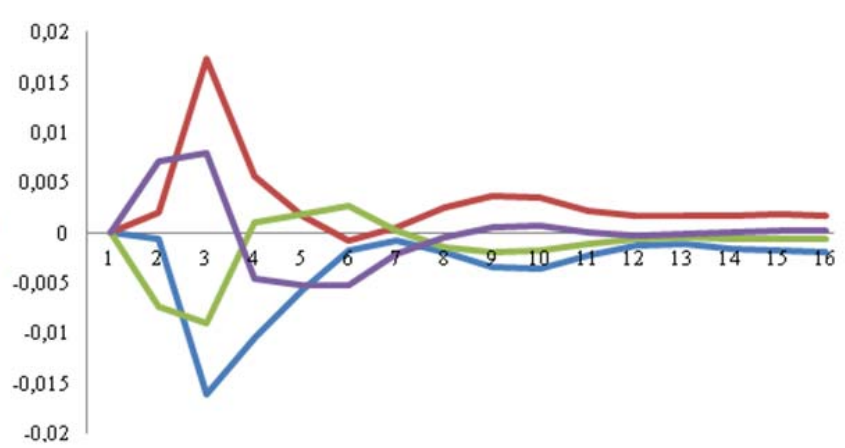

Note: These figures report the response to positive and negative two-standard-deviation shocks. Blue line corresponds to "positive high uncertainty", red line to "negative high uncertainty", green line to "positive low uncertainty" and purple line to "negative low uncertainty". 


\section{Appendix D. The maturity effect of uncertainty}

Figure 1D. Does maturity matter for commodity prices?

Uncertainty effect in energy markets across maturity

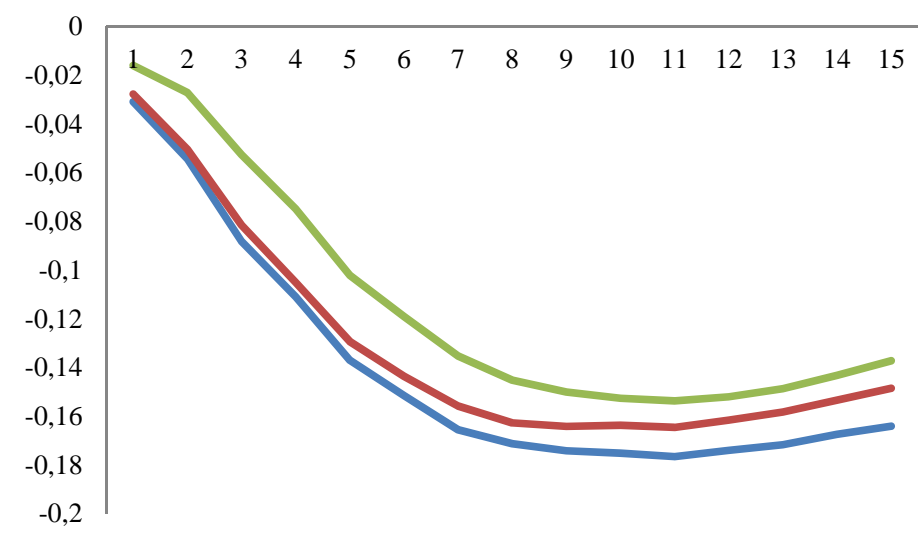

Uncertainty effect in industrial prices across maturity

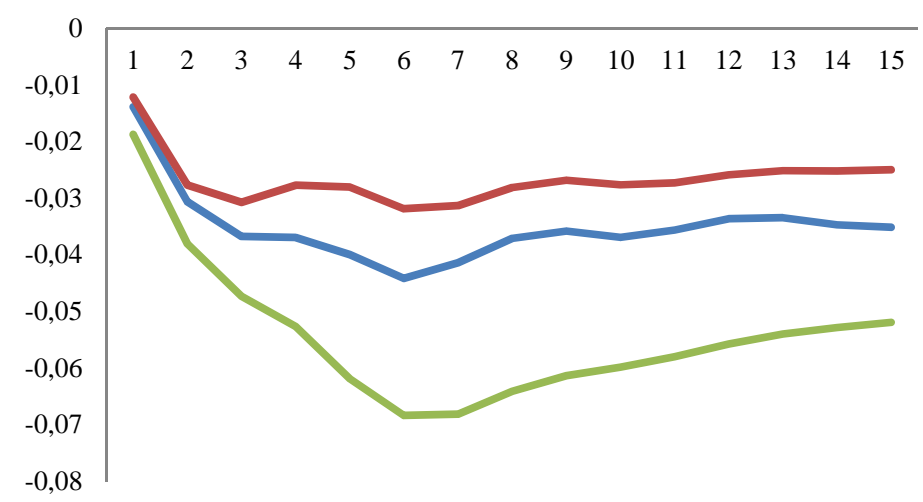

Uncertainty effect in precious metals markets across maturity

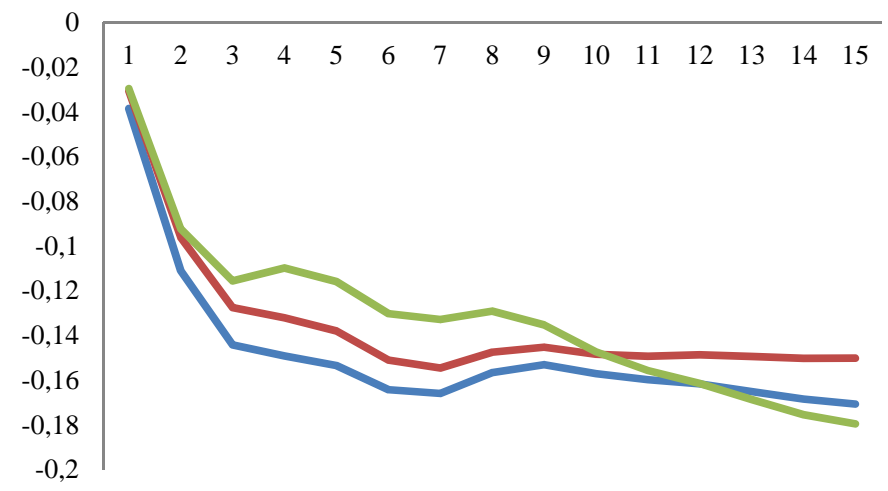

Uncertainty effect in agricultural markets across maturity

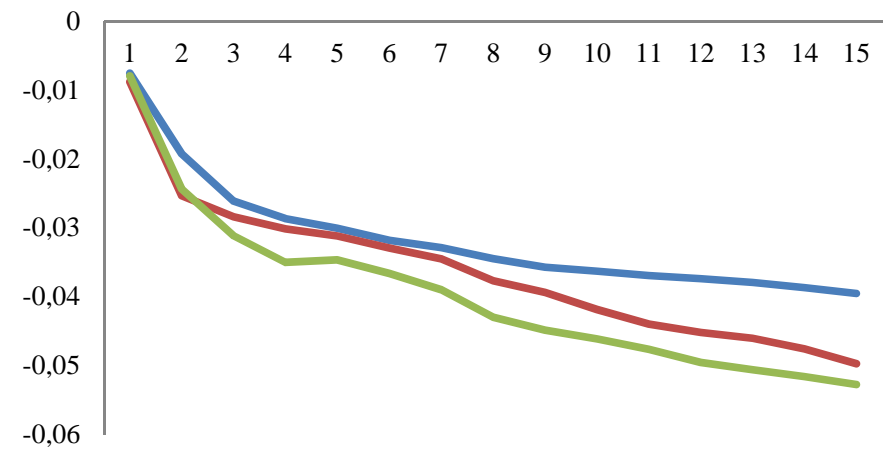

Note: This figure reports the average (per group of markets) cumulative responses of prices to positive two-standard-deviation shocks at maturity $h$. In blue: $h=1$; in red: $h=3$; in green: $h=12$. 
Figure 2D. Does maturity matter for oil prices?

Uncertainty effect in oil price across maturity (positive shocks)

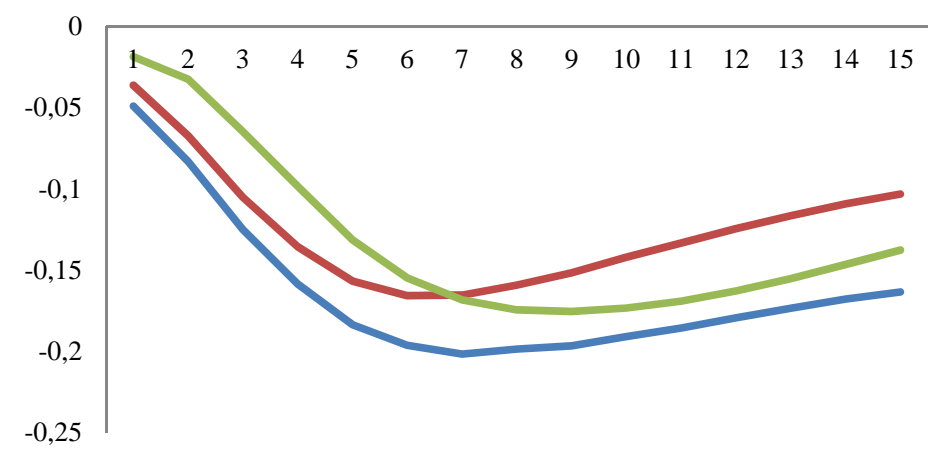

Uncertainty effect in oil price across maturity (negative shocks)

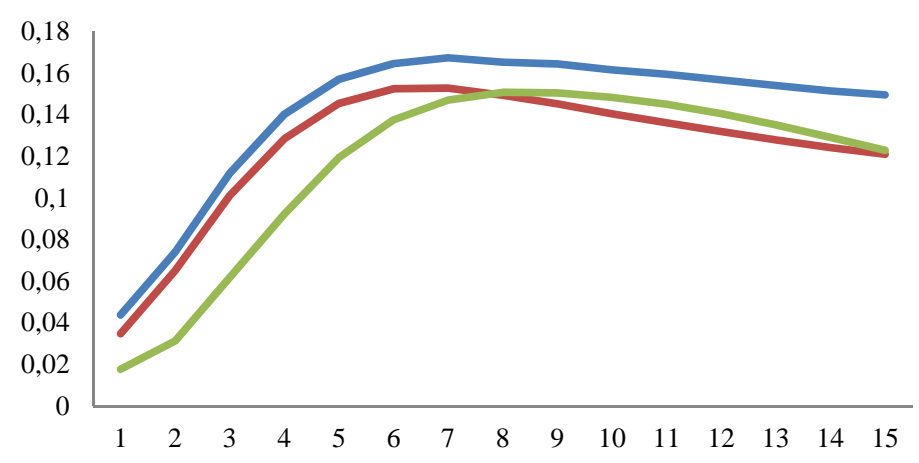

Note: This figure reports the cumulative responses of oil prices to positive (left) and negative (right) two-standard-deviation shocks at maturity $h$. In blue: $h=1$; in red: $h=3$; in green: $h=12$. 


\section{Appendix E. Commodity uncertainty}

Figure 1E. Uncertainty in energy markets
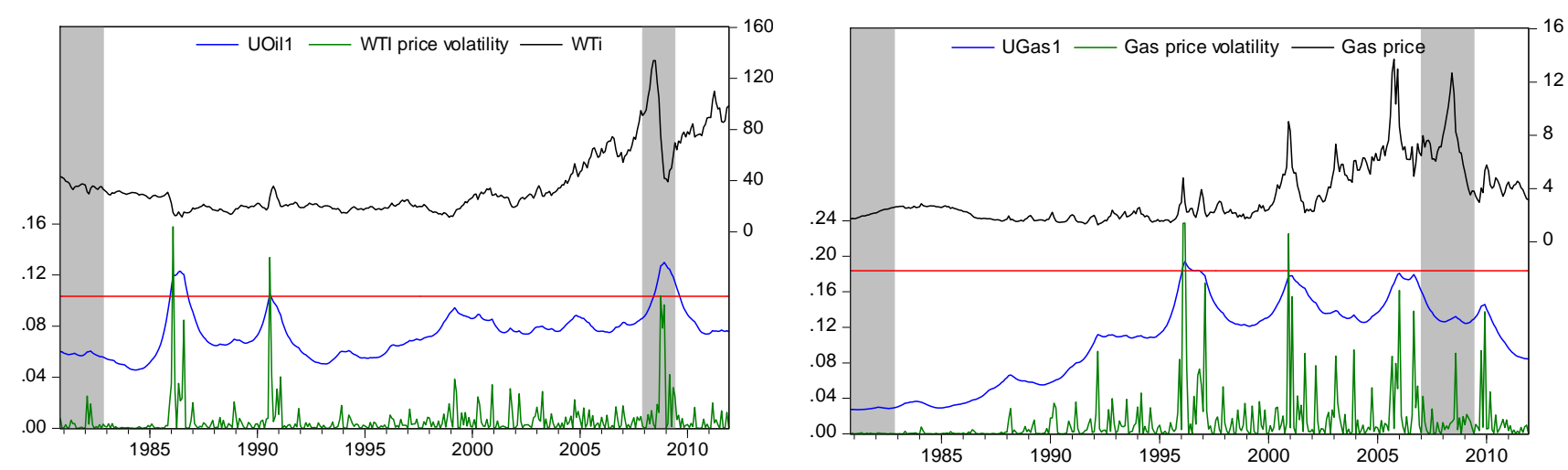

Note: These figures depict uncertainty proxy for energy markets at 1 month (left axis, blue line). The horizontal red bar corresponds to 1.65 standard deviation above the mean of the series (left axis). Vertical gray bands represent macroeconomic uncertainty periods. Volatility (green line) is proxied by the daily squared returns of prices (left axis). Black line refers to price series (right axis). 
Figure 2E. Uncertainty in precious metals markets

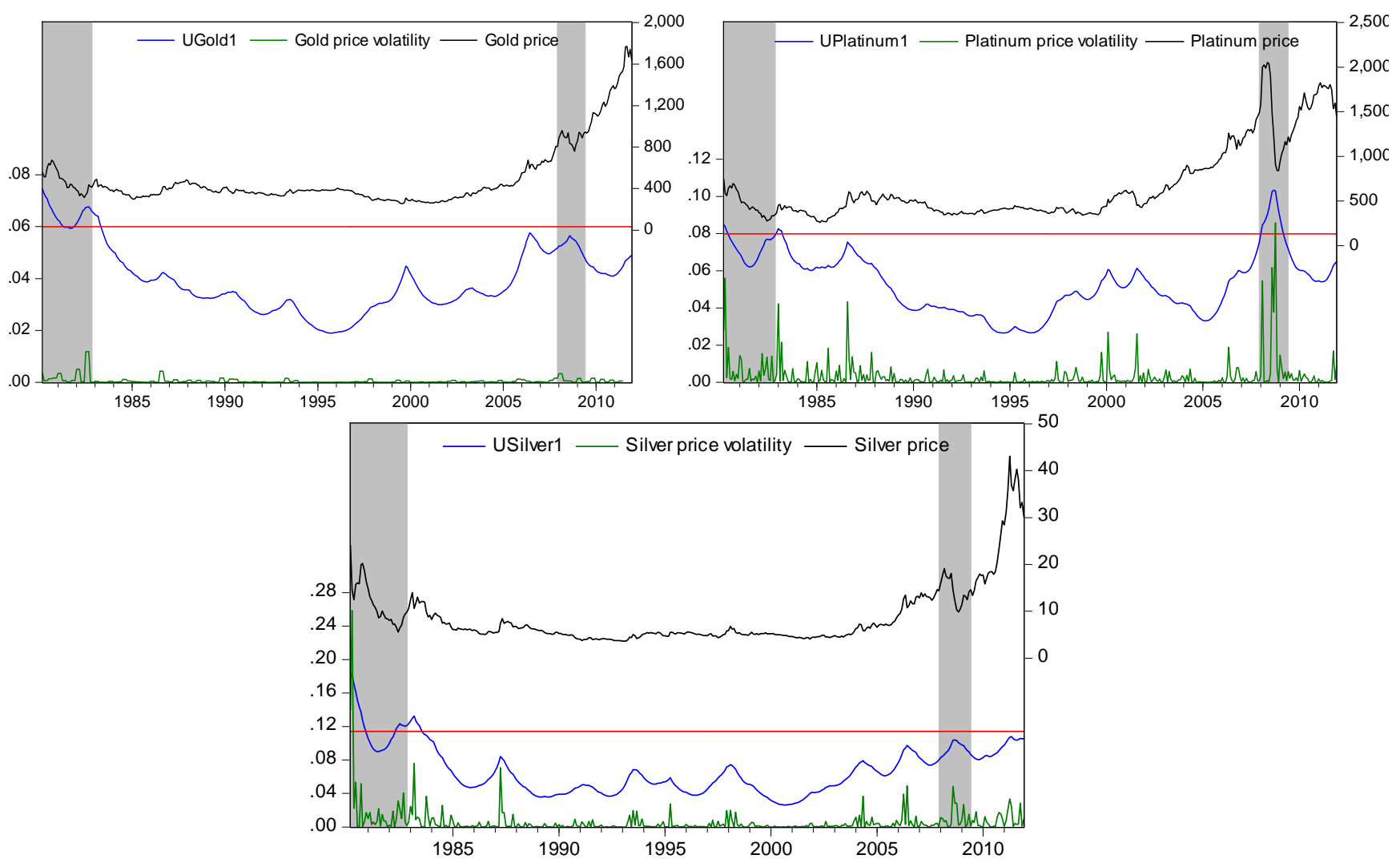

Note: These figures depict uncertainty proxy for precious metals markets at 1 month (left axis, blue line). The horizontal red bar corresponds to 1.65 standard deviation above the mean of the series (left axis). Vertical gray bands represent macroeconomic uncertainty periods. Volatility (green line) is proxied by the daily squared returns of prices (left axis). Black line refers to price series (right axis). 
Figure 3E. Uncertainty in industrial markets
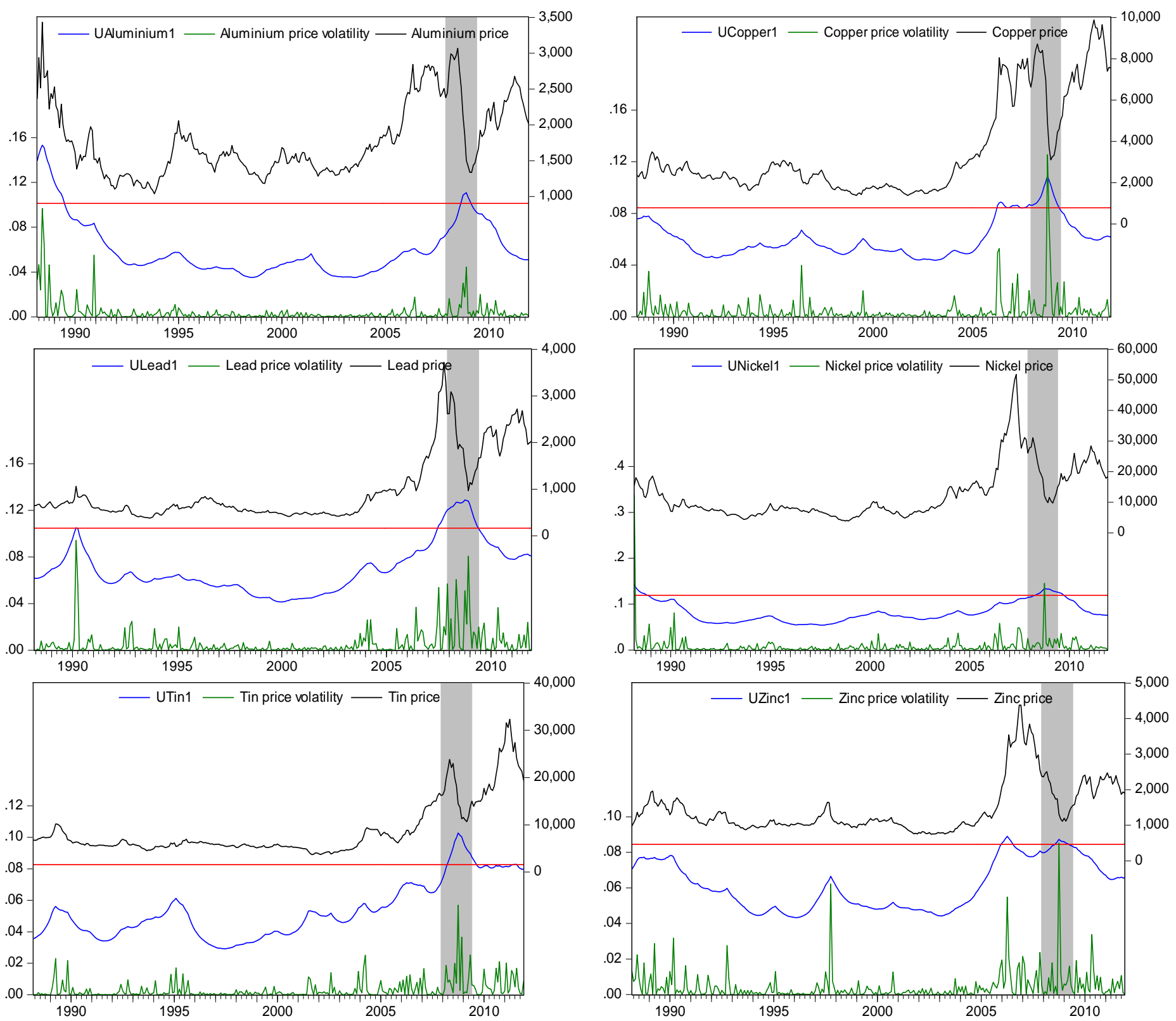

Note: These figures depict uncertainty proxy for industrial markets at 1 month (left axis, blue line). The horizontal red bar corresponds to 1.65 standard deviation above the mean of the series (left axis). Vertical gray bands represent macroeconomic uncertainty periods. Volatility (green line) is proxied by the daily squared returns of prices (left axis). Black line refers to price series (right axis). 
Figure 4E. Uncertainty in agricultural markets
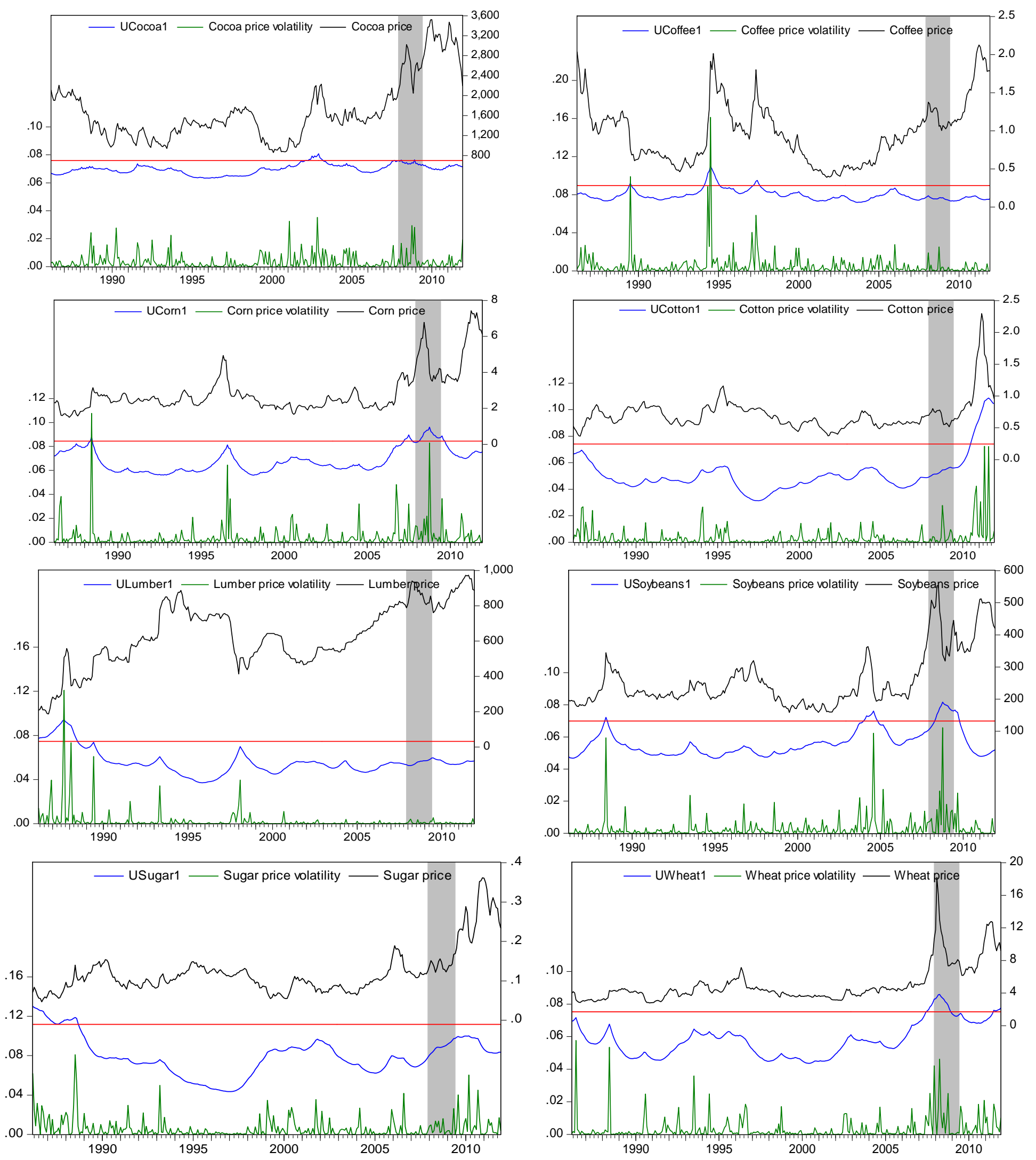

Note: These figures depict uncertainty proxy for agricultural markets at 1 month (left axis, blue line). The horizontal red bar corresponds to 1.65 standard deviation above the mean of the series (left axis). Vertical gray bands represent macroeconomic uncertainty periods. Volatility (green line) is proxied by the daily squared returns of prices (left axis). Black line refers to price series (right axis). 


\section{Appendix F. Historical decomposition analysis}

Figure 1F. Historical decomposition of commodity prices uncertainty with respect to macroeconomic uncertainty

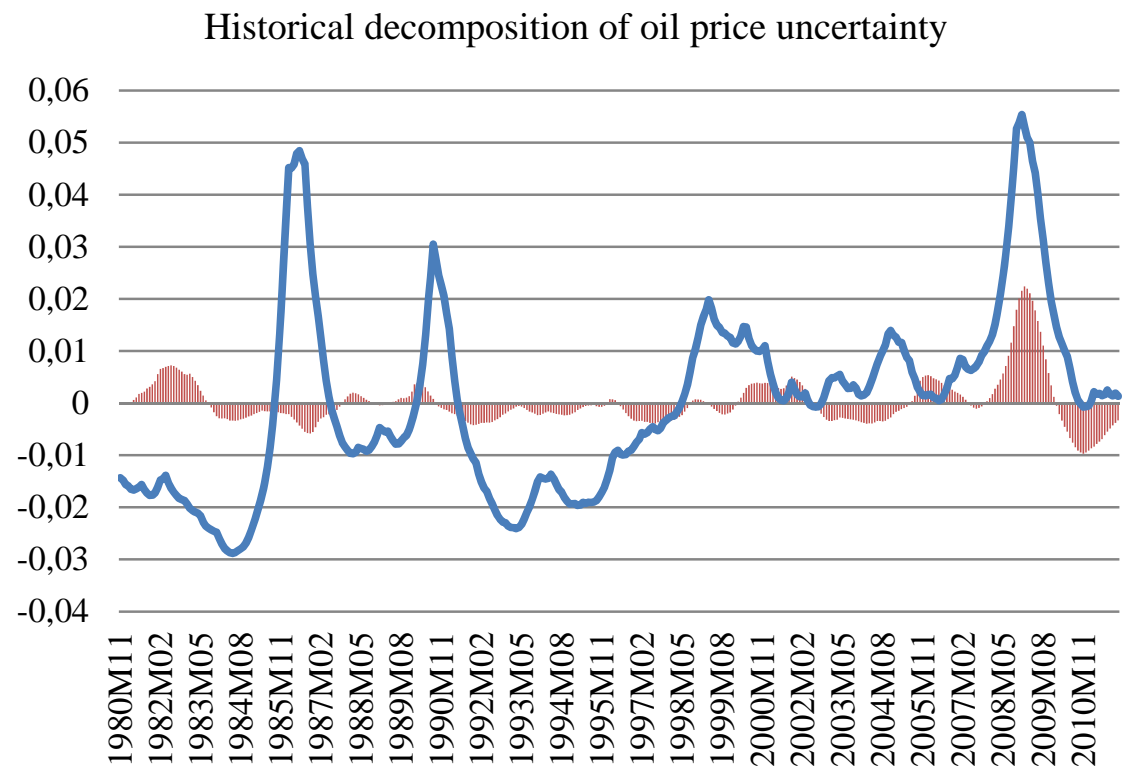

Historical decomposition of copper price uncertainty

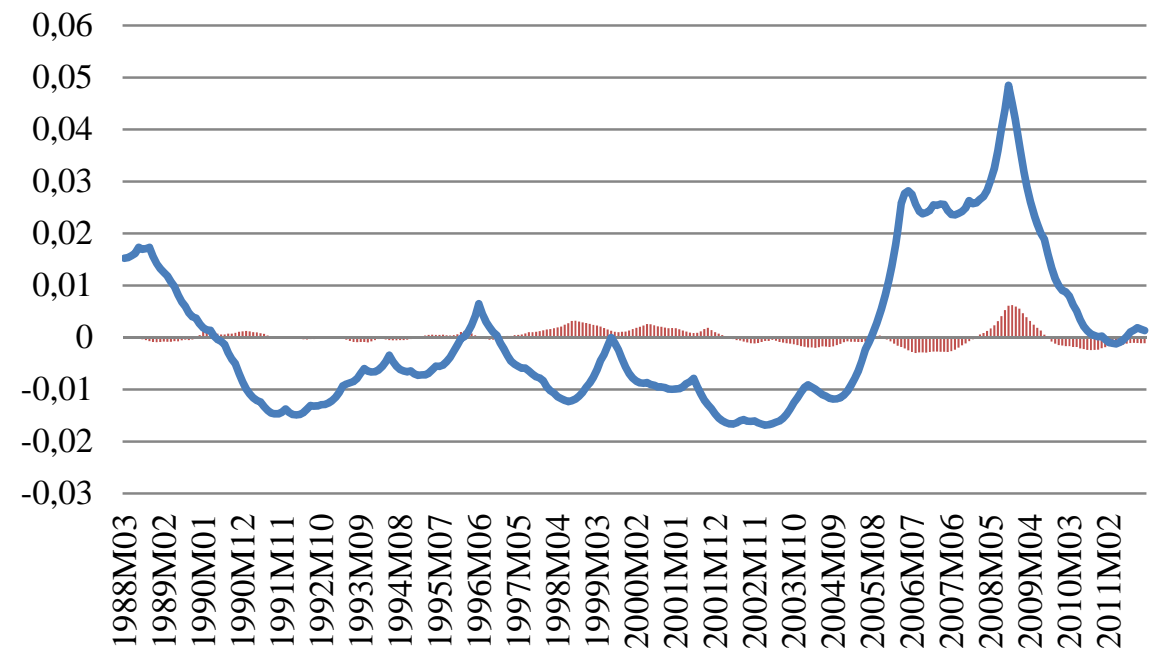

Note: Oil price uncertainty corresponds to the blue line, the proportion of macroeconomic uncertainty is in red. 


\section{Appendix G. Accounting for the type of shock}

Figure 1G. Historical decomposition of oil price uncertainty with respect to supply and demand shocks

Contribution of flow demand shock to oil price uncertainty (global business cycle)

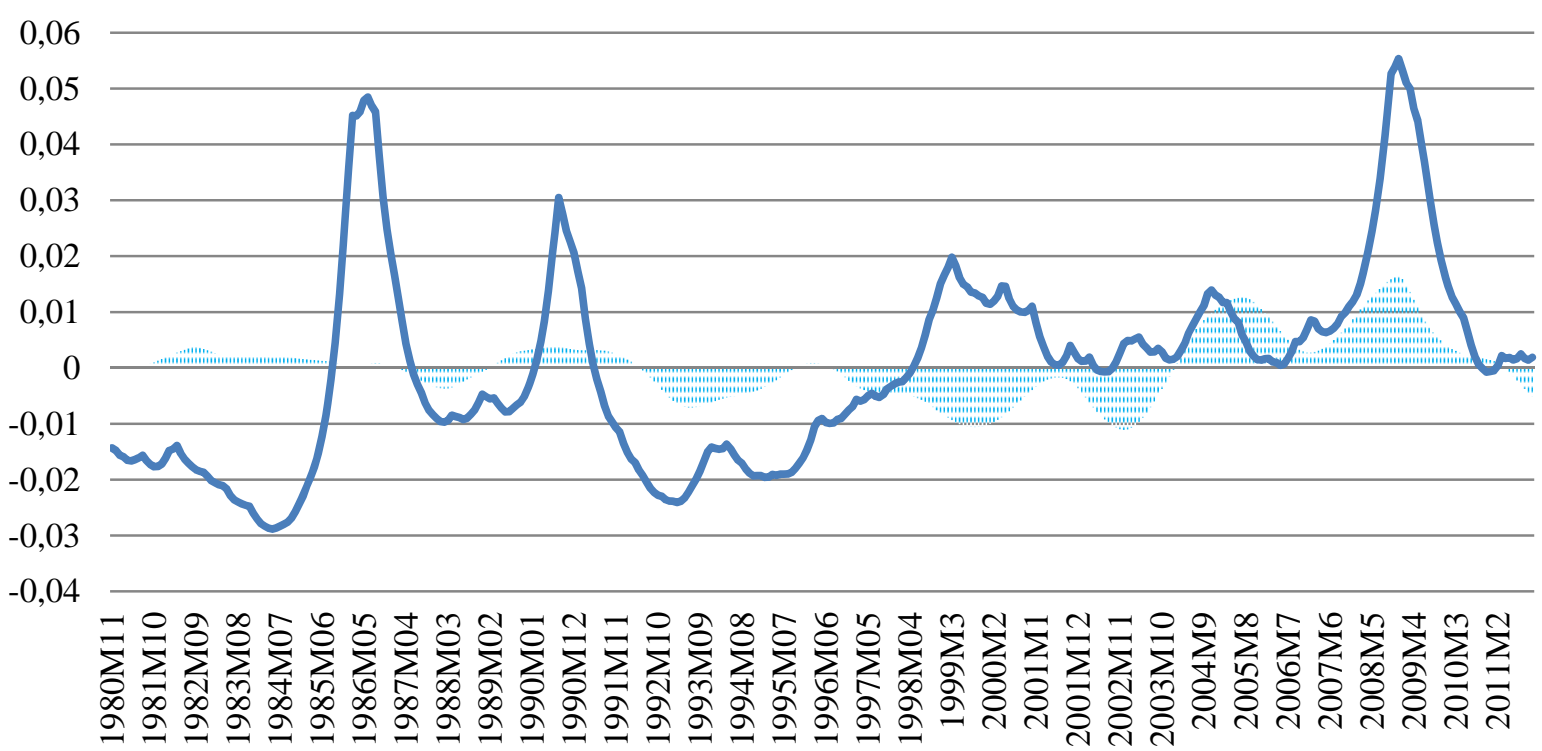

Contribution of flow supply shock to oil price uncertainty (Saudi Arabia production)

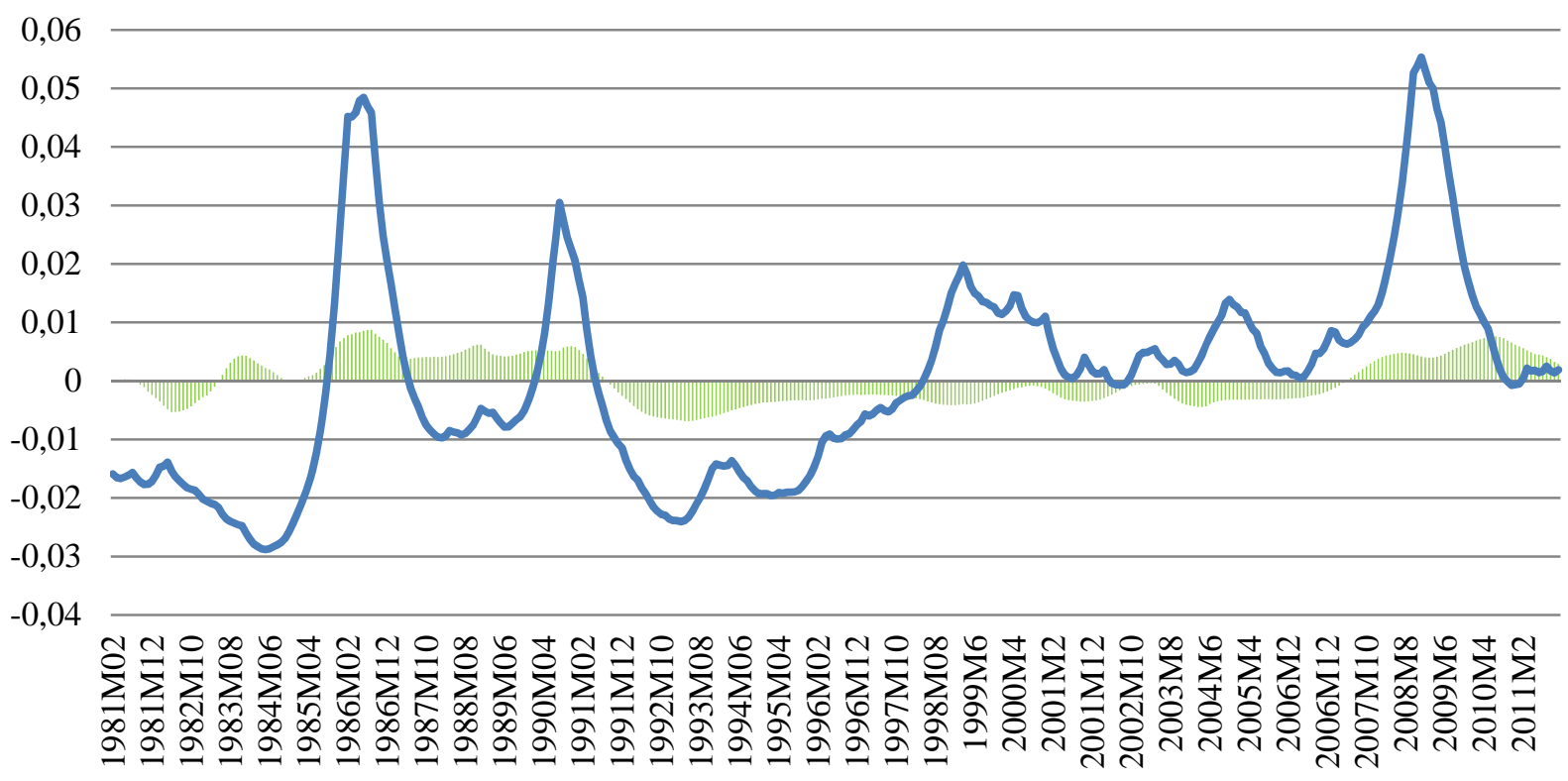


Contribution of speculative demand shock to oil price uncertainty (inventories)

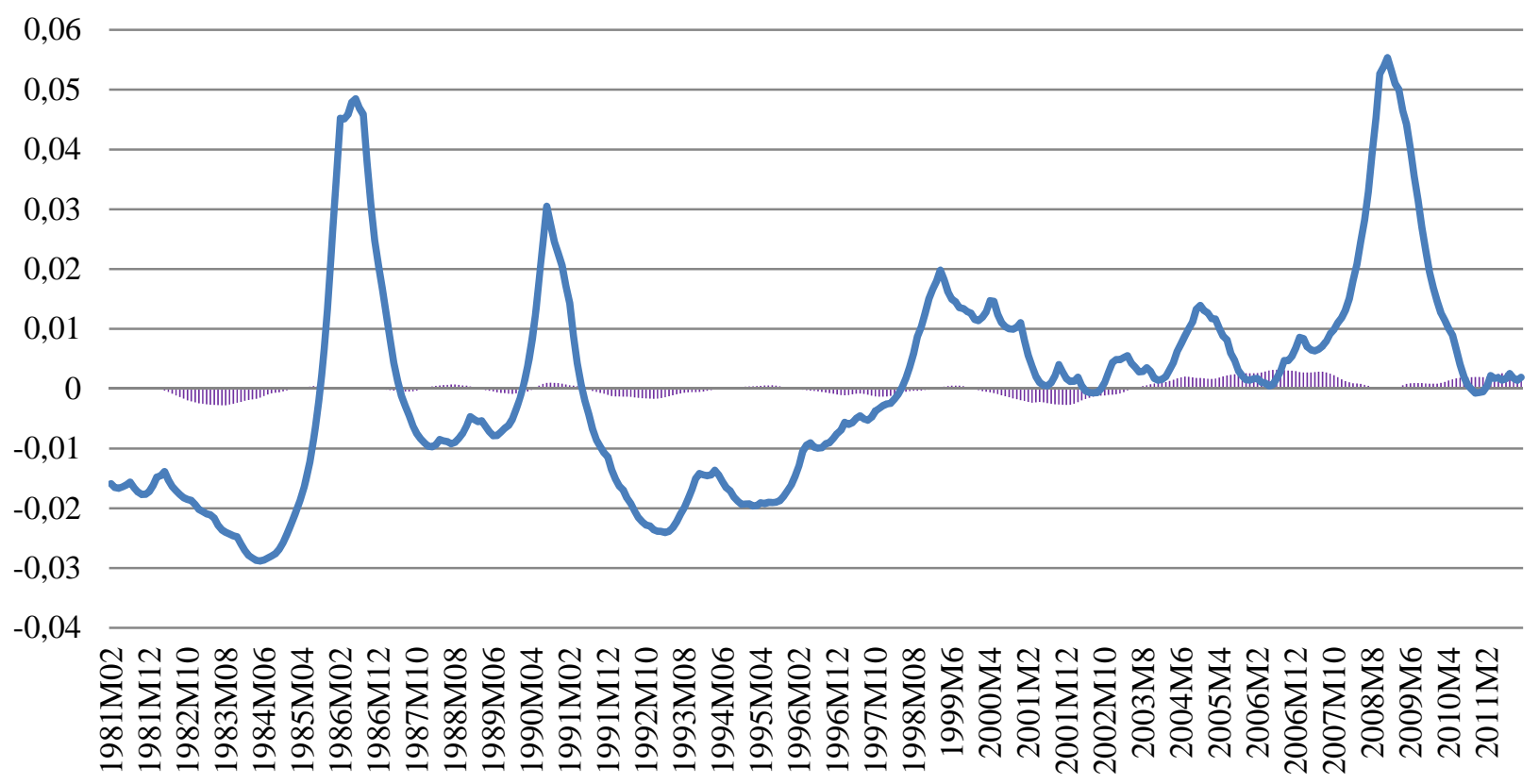

Note: These figures depict the contribution of each shock to oil price uncertainty. The blue line corresponds to oil price uncertainty at 1 month. The contribution of the flow demand (global business cycle) is in blue, the contribution of the flow supply shock (Saudi Arabia crude oil production) is in green, and the contribution of the speculative oil demand shock (inventories) is in purple. 
Figure 2G. Historical decomposition of oil price uncertainty with respect to supply and demand, macroeconomic uncertainty shocks

Contribution of each shocks to oil price uncertainty

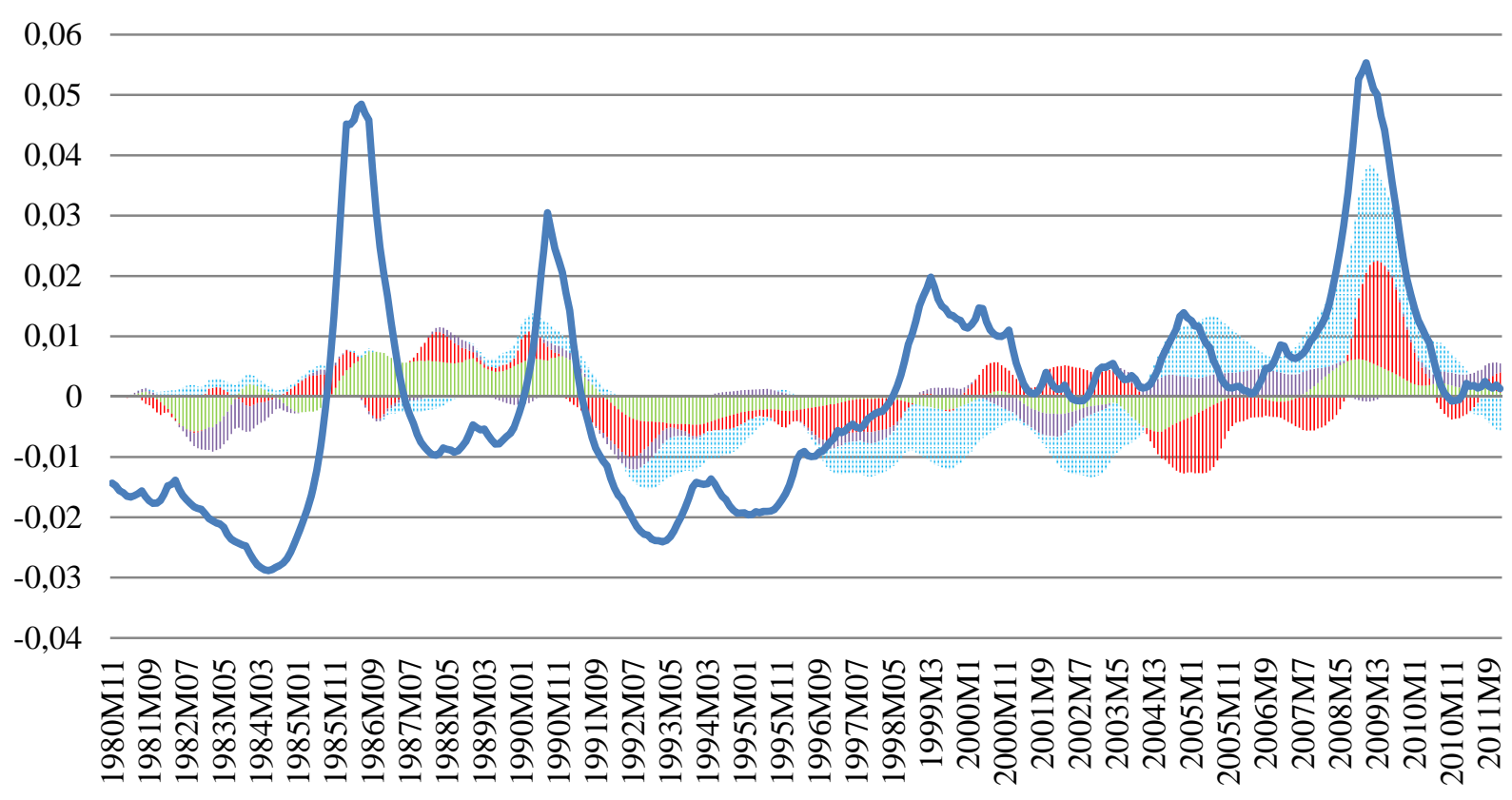

Note: This figure depicts the contribution of each shock to oil price uncertainty. The blue line corresponds to oil price uncertainty at 1 month. The contribution of the flow demand (global business cycle) is in blue, the contribution of the macroeconomic uncertainty at 1 month is in red, the contribution of the flow supply shock (Saudi Arabia crude oil production) is in green, and the contribution of speculative oil demand shock (inventories) is in purple. 


\section{Appendix H. Volatility or predictability?}

Figure $1 \mathrm{H}$. Volatility vs. predictability in the high-uncertainty regime

Response of oil price to VXO and h1 shocks

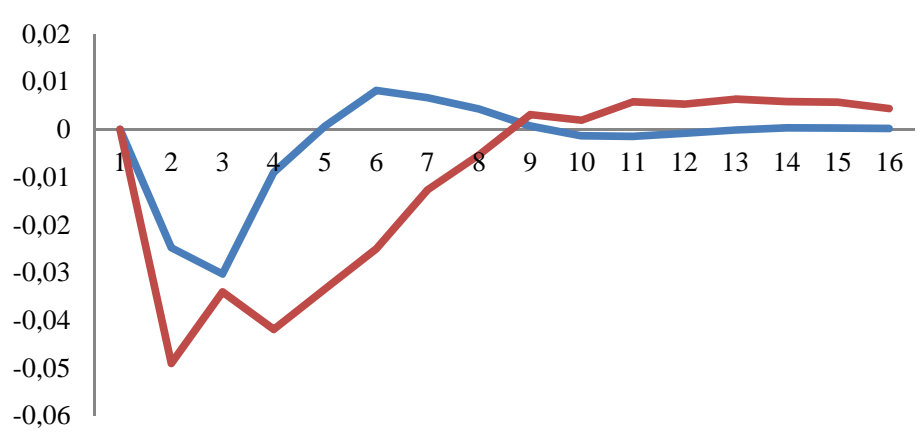

Response of copper price to VXO and h1 shocks

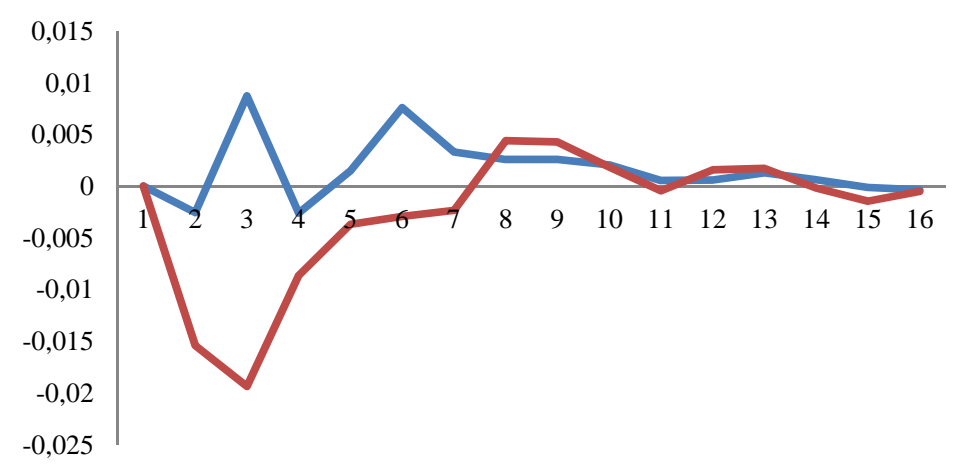

Response of gold price to VXO and h1 shocks

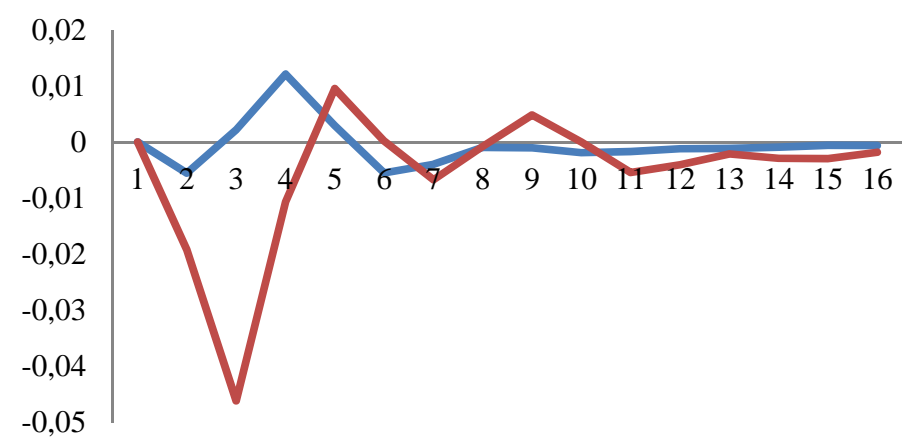

Response of cotton price to VXO and h1 shocks

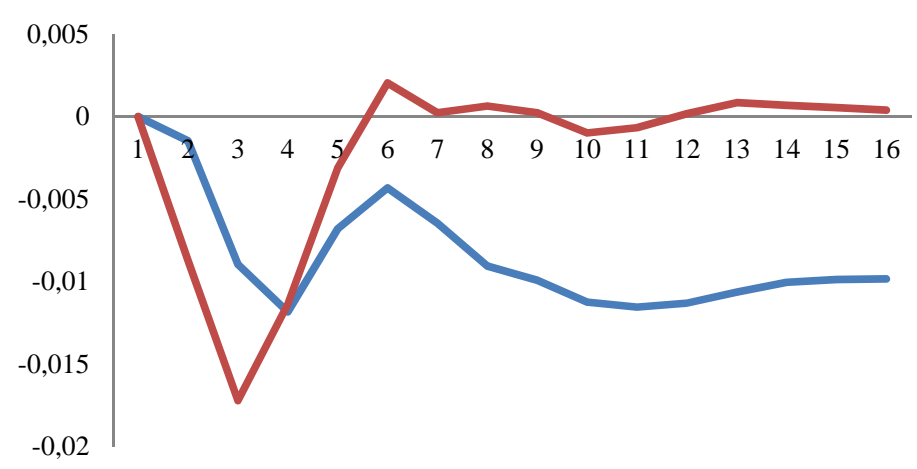

Note: These figures report the response to positive two-standard-deviation VXO (blue line) and $h 1$ (red line) shocks in the high-uncertainty regime. 
Figure 2H. Volatility vs. predictability, commodity uncertainty
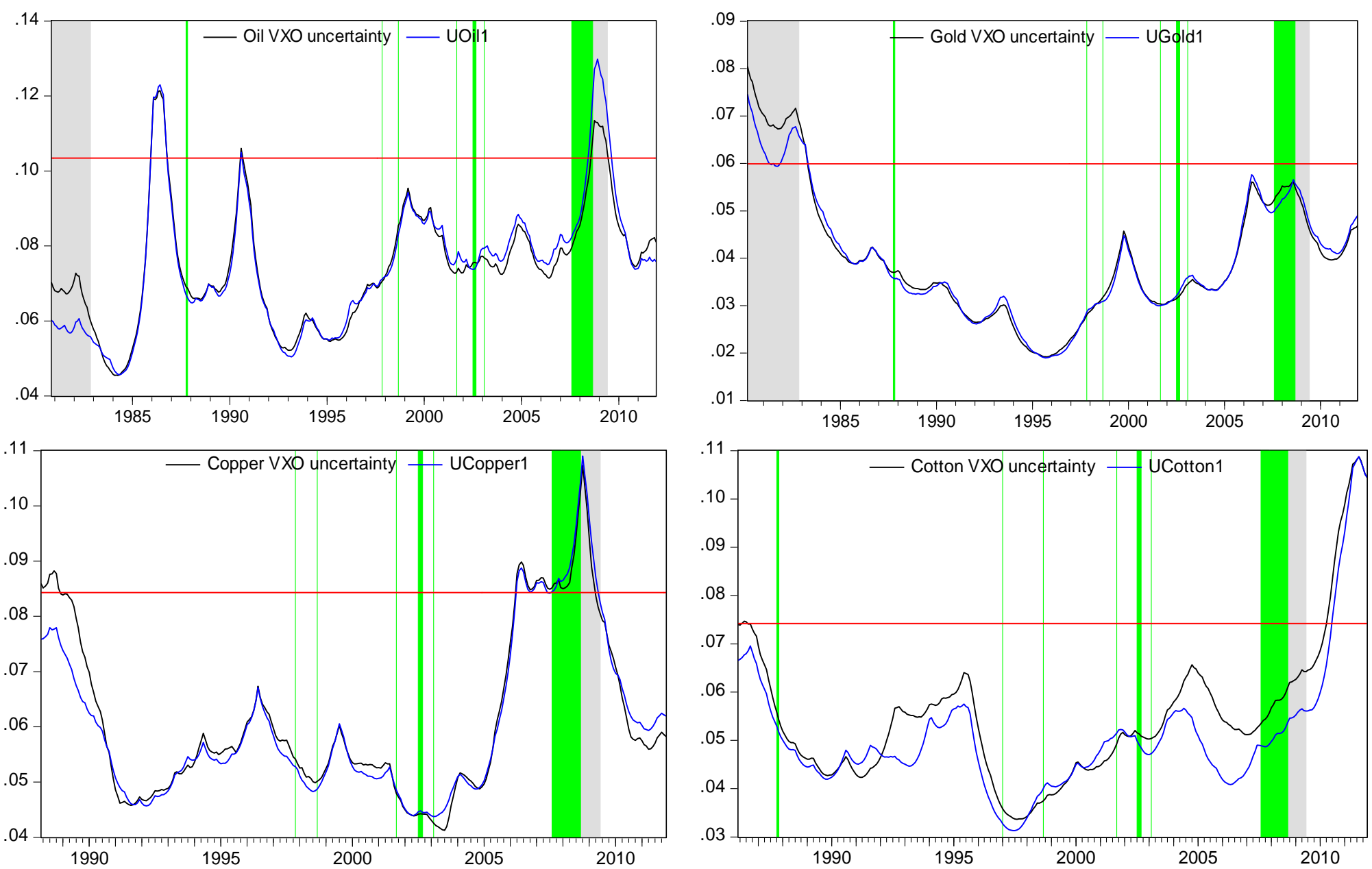

Note: These figures depict the evolution of uncertainty in commodity markets estimated using Jurado et al. (2014)'s approach (blue line) and Bloom (2009)'s approach (black line). The horizontal line is the 1.65 standard deviation above the unconditional mean. The vertical lines correspond to uncertainty episodes detected with Bloom (2009)'s measure (in green) and Jurado et al. (2014)'s measure (in gray). 